\title{
Lipid transfer proteins: classification, nomenclature, structure, and function
}

\author{
Tiina A. Salminen ${ }^{1} \cdot$ Kristina Blomqvist $^{2} \cdot$ Johan Edqvist $^{2}[$
}

Received: 4 June 2016/Accepted: 10 August 2016/Published online: 25 August 2016

(c) The Author(s) 2016. This article is published with open access at Springerlink.com

\begin{abstract}
The non-specific lipid transfer proteins (LTPs) constitute a large protein family found in all land plants. They are small proteins characterized by a tunnel-like hydrophobic cavity, which makes them suitable for binding and transporting various lipids. The LTPs are abundantly expressed in most tissues. In general, they are synthesized with an N-terminal signal peptide that localizes the protein to spaces exterior to the plasma membrane. The in vivo functions of LTPs are still disputed, although evidence has accumulated for a role in the synthesis of lipid barrier polymers, such as cuticular waxes, suberin, and sporopollenin. There are also reports suggesting that LTPs are involved in signaling during pathogen attacks. LTPs are considered as key proteins for the plant's survival and colonization of land. In this review, we aim to present an overview of the current status of LTP research and also to discuss potential future applications of these proteins. We update the knowledge on 3D structures and lipid binding and review the most recent data from functional investigations, such as from knockout or overexpressing experiments. We also propose and argument for a novel system for the classification and naming of the LTPs.
\end{abstract}

Keywords NsLTP · LTP · Cutin · Suberin · Pollen · Protein structure

Johan Edqvist

johan.edqvist@liu.se

1 Structural Bioinformatics Laboratory, Biochemistry, Faculty of Science and Engineering, Åbo Akademi University, 20520 Turku, Finland

2 IFM, Linköping University, 58183 Linköping, Sweden

\section{Introduction}

The non-specific lipid transfer proteins (LTPs) were first discovered approximately 35 years ago. Since then the LTP family has expanded, but it has still kept its secrets unrevealed for plant biologists. The LTPs are found in all land plants, encoded by large gene families, and abundantly expressed in most tissues. Their vast abundance indicates their importance for the survival and reproduction of plants. A search on PubMed in October 2015 with the terms "plant" and "lipid transfer protein" revealed more than 700 papers published dealing with different aspects of the LTPs. A quite large proportion of these reports, approximately $30 \%$, are focusing on the allergenic properties of the LTPs. There are also many publications that cover different biochemical aspects, such as their structure, ligand binding, and regulation. However, although a quite large number of reports have been published, we still have a rather limited understanding of the basic physiological function of the LTPs. This is probably due to that it has been difficult to find good tools and strategies for conclusive experiments. In recent years though, several papers have appeared that reveal phenotypes after knocking-down, knocking-out or increasing the expression of LTPs. It seems that we are slowly gaining some functional understanding of these proteins. Therefore, it is a good time to review the literature, present the current ideas regarding the biological function, and discuss the future directions for research about the LTPs.

\section{Features and classification of LTPs}

The LTPs are small and soluble, cysteine-rich proteins. Their molecular size is usually below $10 \mathrm{kDa}$ (Kader 1996). They possess four or five $\alpha$-helices, which are 
stabilized by four conserved disulfide bridges formed by an eight-Cys motif (8CM) with the general form C-Xn-C-Xn$\mathrm{CC}-\mathrm{Xn}-\mathrm{CXC}-\mathrm{Xn}-\mathrm{C}-\mathrm{Xn}-\mathrm{C}$. The disulfide bridges promote the folding of the LTP into a very compact structure, which is extremely stable to heat and denaturation agents (Lindorff-Larsen and Winther 2001; Berecz et al. 2010; Edstam et al. 2014). The LTPs are in general synthesized with an $\mathrm{N}$-terminal signal peptide that localizes the protein to the apoplastic space. They are abundant in all investigated land plants, but absent from chlorophyte and charophyte green algae as well as all other organisms (Edstam et al. 2011). The LTPs are encoded by large gene families with more than 50 members in many flowering plants and up to 50 members in bryophytes and ferns (Boutrot et al. 2008; Edstam et al. 2011; Li et al. 2014a; Wei and Zhong 2014). Several LTPs are known to cause plant food allergies in humans. Curiously, these LTP allergies are frequent in Mediterranean countries but rare in Northern Europe. The role of LTPs in allergic reactions is not covered in this review where we focus on the biological function of LTPs in plants. We would rather recommend other reviews for an update on this important and interesting aspect of LTPs (Egger et al. 2010; Salcedo et al. 2007; Van Winkle and Chang 2014).

The LTPs are often simply classified into either of the types LTP1 or LTP2. These types differ by their molecular size as LTP1s have about 90 amino acids and LTP2s have about 70 amino acids (Kalla et al. 1994). A second LTP classification system based on sequence identity has also been introduced (Boutrot et al. 2008). When the LTPs were characterized in early diverging plants, such as mosses and liverworts, the LTPs in those plants could not readily be classified into LTP1 or LTP2 due to the variations in molecular size. Furthermore, the limited sequence conservation made it unsuitable to apply the sequence-based sorting system. Therefore, we introduced a modified and expanded LTP-classification system yielding five major types (LTP1, LTP2, LTPc, LTPd, and LTPg) and four minor types with fewer members (LTPe, LTPf, LTPh, LTPj, and LTPk) (Edstam et al. 2011). This classification system is not based on the molecular size, but rather on the position of a conserved intron, the amino acid sequence identity and the spacing between the Cys residues in the 8CM. The system also considers post-translational modifications, e.g., LTPs with a GPI-anchor belong to LTPg. Since this novel classification system assays several features of the LTPs, it is more robust than previous classification systems (Joly and Matton 2015). We would, therefore, recommend it for future classifications of the LTPs. Although the classification system is novel, the conventional classification of LTP1 and LTP2 types is preserved.

\section{Distribution and nomenclature}

When we applied the novel classification system, we found that non-seed plants have a more limited set of LTP types compared with seed plants. This indicates that novel LTP types have evolved during land plant evolution. LTPd and LTPg are found in all investigated land plants from bryophytes to flowering plants and, therefore, represent the earliest LTPs (Edstam et al. 2011). LTP1 and LTPc are restricted to vascular plants, while LTP2 is further limited to seed plants. Since we entered the era of plant genome sequencing, the complete array of LTP genes has been deduced for several plant species (Table 1). Curiously, the genome-wide search of the moss Physcomitrella patens revealed two genes encoding proteins with two connected $8 \mathrm{CMs}$ and another gene encoding three 8CMs (Edstam et al. 2011). So far, the multidomain LTPs are uniquely identified in $P$. patens.

The naming of LTPs has been confusing and without any guidelines or standardization. There are, for instance, several examples where specific LTPs are given different names in separate papers. The lack of a robust naming system has occasionally made it rather difficult, extremely time-consuming and sometimes also frustrating to compare the data from different papers. We would, therefore, encourage the use of a well-defined, simple but informative naming system for the LTPs. The following format is suggested for naming the LTPs: AtLTP1.3, OsLTP2.4, HvLTPc6, PpLTPd5, and TaLTPg7. The first two letters indicate the plant species $(\mathrm{At}=$ Arabidopsis thaliana, $\mathrm{Pp}=$ Physcomitrella patens etc.), LTP1, LTP2, LTPc indicate the type, while the last digit (here 3-7) indicates the specific number given to each gene/protein within a certain LTP type. For clarity, we recommend that a punctuation mark is placed between the type specification and gene number in LTP1 and LTP2. For LTPc, LTPd, LTPg, and other LTP types defined with a letter, the punctuation mark is not needed. This naming system was introduced previously for Marchantia polymorpha, $P$. patens, S. moellendorffi, Adiantum capillus-veneris, Pinus taeda, and Arabidopsis (Edstam et al. 2011, 2013; Joly and Matton 2015) and later used also for maize, Oryza sativa (rice) and sorghum (Wei and Zhong 2014). In this review, we also introduce the novel naming system to LTPs from other plants, such as Hordeum vulgare (barley), Triticum aestivum (wheat), and Nicotiana tabacum (tobacco) (Table 2).

\section{Ligand binding and 3D structure}

\section{Wheat LTP1}

The 3D structures of LTPs have been determined using both NMR spectroscopy and X-ray crystallography, either in free, unliganded form or in a complex with ligands 
Table 1 Distribution of LTPs in some selected plant genomes

\begin{tabular}{|c|c|c|c|c|c|c|c|c|c|c|c|c|}
\hline Plant species & Total LTPs & LTP1 & LTP2 & LTPc & LTPd & LTPe & LTPf & LTPg & $\mathrm{LTPh}$ & LTPj & $\mathrm{LTPk}$ & $\mathrm{LTPx}^{\mathrm{g}}$ \\
\hline Marchantia polymorpha ${ }^{\mathrm{a}, \mathrm{e}}$ & 14 & & & & 8 & & & 4 & & & & 2 \\
\hline Physcomitrella patens ${ }^{\mathrm{a}, \mathrm{f}}$ & 40 & & & & 21 & & & 10 & & 7 & 2 & \\
\hline Selaginella moellendorffi ${ }^{\mathrm{a}, \mathrm{f}}$ & 43 & & & & 19 & 3 & 2 & 12 & 6 & & & 1 \\
\hline Pinus taeda ${ }^{\mathrm{a}, \mathrm{e}}$ & 42 & 9 & 1 & 2 & 12 & & 1 & 17 & & & & \\
\hline Oryza sativa ${ }^{\mathrm{a}, \mathrm{f}}$ & 77 & 20 & 13 & 2 & 12 & & & 27 & & & & 3 \\
\hline Oryza sativa ${ }^{\mathrm{b}, \mathrm{f}}$ & 77 & 18 & 13 & 2 & 14 & & & 27 & & & & 3 \\
\hline Zea mays ${ }^{\mathrm{b}, \mathrm{f}}$ & 51 & 8 & 9 & 2 & 16 & & & 26 & & & & 2 \\
\hline Sorghum bicolor ${ }^{\mathrm{b}, \mathrm{f}}$ & 58 & 9 & 7 & 2 & 13 & & & 24 & & & & 3 \\
\hline Arabidopsis thaliana $^{\mathrm{a}, \mathrm{f}}$ & 79 & 12 & 14 & 3 & 12 & 2 & & 34 & & & & 4 \\
\hline Arabidopsis thaliana ${ }^{\mathrm{b}, \mathrm{f}}$ & 78 & 13 & 13 & 2 & 12 & 2 & & 29 & & & & 7 \\
\hline Arabidopsis thaliana ${ }^{\mathrm{c}, \mathrm{f}}$ & 79 & 12 & 15 & $3^{\mathrm{h}}$ & $12^{\mathrm{i}}$ & $2^{\mathrm{j}}$ & & 31 & & & & $2^{\mathrm{k}}$ \\
\hline Brassica napa ${ }^{\mathrm{d}, \mathrm{f}}$ & 85 & 19 & 15 & $3^{\mathrm{h}}$ & $21^{\mathrm{i}}$ & $3^{\mathrm{j}}$ & & 22 & & & & $2^{\mathrm{k}}$ \\
\hline
\end{tabular}

${ }^{a}$ Edstam et al. (2011)

b Wei and Zhong (2014)

c Boutrot et al. (2008)

${ }^{d}$ Li et al. (2014a)

e Data from cDNA and EST analysis

${ }^{\mathrm{f}}$ Data from genome-wide analysis

g Proteins that fulfill the criteria for LTP but which not share characteristics with the other LTP types are placed in the column LTPx

h Type III in Boutrot et al. (2008) and Li et al. (2014a)

i Types IV, V, VI, VIII, and XI in Boutrot et al. (2008) and Li et al. (2014a)

$\mathrm{j}$ Type IX in Boutrot et al. (2008) and Li et al. (2014a)

${ }^{\mathrm{k}}$ NsLTPy in Boutrot et al. (2008) and Li et al. (2014a)

(liganded form). The first 3D structure of an LTP was established on the basis of 3D and $2 \mathrm{D}{ }^{1} \mathrm{H}-\mathrm{NMR}$ data of an aqueous solution of TaLTP1.1 purified from wheat seeds (Simorre et al. 1991; Gincel et al. 1994: Protein Data Bank Identification Code (PDB ID) 1GH1). The structure revealed four helices linked together by flexible loops and packed against the unstructured C-terminal part (Fig. 1a), which is stabilized by several hydrogen bonds. The four disulfide bridges formed by the eight Cys in the $8 \mathrm{CM}$ stabilize the fold of the protein. Both the N-terminal end of helix $1(\mathrm{H} 1)$ and the C-terminal part are linked to helix 3 (H3) by disulfide bridges (marked 1 and 4 in Fig. 1a), respectively. The position of helix 2 (H2) is stabilized by two disulfide bonds; one of them links the N-terminal part of $\mathrm{H} 2$ to the $\mathrm{C}$-terminal part of $\mathrm{H} 1$ and the other one links $\mathrm{H} 2$ to helix 4 (H4) (bridges 2 and 3 in Fig. 1a). The central hydrophobic cleft is formed by the residues from $\mathrm{H} 1$ (Val10 and Leu14), H2 (Val31, Leu34, and Ala38), H3 (Ala47, Leu51, and Ala54), and loop H3-H4 (Ile58), H4 (Ile69), and from the C-terminal part (Leu77, Tyr79, and Ile81) (Fig. 1b).

Glycerophospholipids, such as derivatives of phosphatidylglycerol (PG) or phosphatidylcholine (PC), are important membrane components in most cells. In plants, PG is an important component of the thylakoids, whereas
PC makes up a very high proportion of the outer leaflet of the plasma membrane. According to experiments performed with ${ }^{1} \mathrm{H}$ NMR and fluorescence spectroscopy, the wheat LTP TaLTP1.1 can fit the PG derivative 1,2dimyristoyl phosphatidylglycerol (DMPG) in its binding cavity (Sodano et al. 1997). In DMPG, two myristoyl chains are connected to the sn 1 and sn2 positions of the PG backbone. In the TaLTP1.1:DMPG complex, both acyl chains are accommodated into the hydrophobic cavity. The volume of the cavity was estimated to be $750 \pm 250 \AA^{3}$ when occupied by the two acyl chains. The fold of the LTP was only weakly affected by the insertion of the bulky lipid. The only structural alteration induced by DMPG is seen in the C-terminal part of the structure where the aromatic ring of Tyr79 is directed outwards into the solvent in the TaLTP1.1:DMPG complex, excluding the formation of hydrogen bonds between DMPG and TaLTP1.1.

Experiments assaying the ligand binding of LTPs are often based on competition between labeled lipid analogs and unlabeled fatty acids or lipids. Fluorescent fatty acid analogs, such as anthroyloxy-fatty acids, 1-pyrenedodecanoic acid (P-96), and 2-p-toluidinonaphtalene-6-sulfonate (TNS), have been useful tools in the competition assays (Buhot et al. 2004; Zachowski et al. 1998). When the capacity of fatty acids to displace 
Table 2 The LTPs described in this review

\begin{tabular}{|c|c|c|c|}
\hline Species & $\begin{array}{l}\text { Current name } \\
\text { (This publication) }\end{array}$ & $\begin{array}{l}\text { Other names (Miscellaneous } \\
\text { publications) }\end{array}$ & UniProt Id \\
\hline \multirow[t]{24}{*}{ Triticum aestivum (wheat) } & TaLTP1.1 & $\begin{array}{l}\text { LTP1 (Gincel et al. 1994; Charvolin et al. } \\
\text { 1999), TaLtp9.1a (Boutrot et al. 2007); } \\
\text { TaLtpIa.1 (Boutrot et al. 2008) }\end{array}$ & P24296; Q8GZB0 \\
\hline & TaLTP1.2 & $\begin{array}{l}\text { TaLtp9.1b (Boutrot et al. 2007); TaLtpIa.2 } \\
\text { (Boutrot et al. 2008) }\end{array}$ & Q5NE27 \\
\hline & TaLTP1.3 & $\begin{array}{l}\text { TaLtp9.2b (Boutrot et al. 2007) ; TaLtpIb.1 } \\
\quad \text { (Boutrot et al. 2008) }\end{array}$ & Q5NE28 \\
\hline & TaLTP1.4 & $\begin{array}{l}\text { TaLtp9.2c (Boutrot et al. 2007); TaBs116G9 } \\
\text { (Sun et al. 2008); TaLtpIb.2 (Boutrot et al. } \\
\text { 2008) }\end{array}$ & Q2PCC2 \\
\hline & TaLTP1.5 & $\begin{array}{l}\text { TaLtp9.2d (Boutrot et al. 2007); TaLtpIb.3 } \\
\text { (Boutrot et al. 2008) }\end{array}$ & Q2PCC1 \\
\hline & TaLTP1.6 & $\begin{array}{l}\text { TaLtp9.3a (Boutrot et al. 2007); TaLtpIc.1 } \\
\text { (Boutrot et al. 2008) }\end{array}$ & Q5NE30 \\
\hline & TaLTP1.7 & $\begin{array}{l}\text { TaLtp9.3b (Boutrot et al. 2007); TaLtpIc.2 } \\
\text { (Boutrot et al. 2008) }\end{array}$ & Q2PCE0 \\
\hline & TaLTP1.8 & $\begin{array}{l}\text { TaLtp9.3c (Boutrot et al. 2007); TaLtpIc.3 } \\
\quad \text { (Boutrot et al. 2008) }\end{array}$ & Q2PCD9 \\
\hline & TaLTP1.9 & $\begin{array}{l}\text { TaLtp9.3d (Boutrot et al. 2007); TaLtpIc.4 } \\
\text { (Boutrot et al. 2008) }\end{array}$ & Q2PCB9 \\
\hline & TaLTP1.10 & $\begin{array}{l}\text { TaLtp9.3e (Boutrot et al. 2007); TaLtpIc.5 } \\
\text { (Boutrot et al. 2008) }\end{array}$ & Q2PCD7 \\
\hline & TaLTP1.11 & $\begin{array}{l}\text { TaLtp9.3f (Boutrot et al. 2007); TaLtpIc.6 } \\
\text { (Boutrot et al. 2008) }\end{array}$ & Q5NE33 \\
\hline & TaLTP1.12 & $\begin{array}{l}\text { TaLtp9.3g (Boutrot et al. 2007); TaLtpIc.7 } \\
\text { (Boutrot et al. 2008) }\end{array}$ & Q2PCD4 \\
\hline & TaLTP1.13 & $\begin{array}{l}\text { TaLt19C10, TaBs112C7 (Gaudet et al. 2003; } \\
\text { Sun et al. 2008); TaLtpIb.5 (Boutrot et al. } \\
\text { 2008) }\end{array}$ & Q1KMU9 \\
\hline & TaLTP1.14 & $\begin{array}{l}\text { TaLtp9.4a (Boutrot et al. 2007); TaLtpId.1 } \\
\text { (Boutrot et al. 2008); Qfhs.ifa-5A } \\
\text { (Schweiger et al. 2013) }\end{array}$ & Q5NE29 \\
\hline & TaLTP1.15 & $\begin{array}{l}\text { TaLtp9.4b (Boutrot et al. 2007); TaLtpId.2 } \\
\text { (Boutrot et al. 2008) }\end{array}$ & Q2PCB6 \\
\hline & TaLTP1.16 & $\begin{array}{l}\text { TaLTP3 (Jang et al. 2005; Saltzmann et al. } \\
\text { 2010; Wang et al. 2010); TaLtp9.4c } \\
\text { (Boutrot et al. 2007); TaLtpId.3 (Boutrot } \\
\text { et al. 2008) }\end{array}$ & Q84N29 \\
\hline & TaLTP1.17 & $\begin{array}{l}\text { TaLTP1 (Jang et al. 2005); TaLtp9.5a } \\
\text { (Boutrot et al. 2007); TaLt710H24 (Sun } \\
\text { et al. 2008); TaLtpIb.33 (Boutrot et al. } \\
\text { 2008) }\end{array}$ & Q9FUK0 \\
\hline & TaLTP1.18 & $\begin{array}{l}\text { TaLTP2 (Jang et al. 2005); TaLtp9.5b } \\
\text { (Boutrot et al. 2007); TaLt709L6 (Sun } \\
\text { et al. 2008); TaLtpIb.34 (Boutrot et al. } \\
\text { 2008) }\end{array}$ & Q9ATG4 \\
\hline & TaLTP1.19 & $\begin{array}{l}\text { TaLtp9.6a (Boutrot et al. 2007); TaLtpIf.1 } \\
\text { (Boutrot et al. 2008) }\end{array}$ & Q5NE32 \\
\hline & TaLTP1.20 & $\begin{array}{l}\text { TaLtp9.7a (Boutrot et al. 2007); TaLtpIg.1 } \\
\text { (Boutrot et al. 2008) }\end{array}$ & Q5NE31 \\
\hline & TaLTP1.21 & $\begin{array}{l}\text { TaLtp9.7b (Boutrot et al. 2007); TaLtpIg.2 } \\
\text { (Boutrot et al. 2008) }\end{array}$ & Q2PCD2 \\
\hline & TaLTP1.22 & $\begin{array}{l}\text { TaLtp9.7c (Boutrot et al. 2007); TaLtpIg.3 } \\
\text { (Boutrot et al. 2008) }\end{array}$ & Q2PCD1 \\
\hline & TaLTP1.23 & $\begin{array}{l}\text { TaLtp9.7d (Boutrot et al. 2007); TaLtpIg.4 } \\
\text { (Boutrot et al. 2008); Hfr-LTP (Saltzmann } \\
\text { et al. 2010) }\end{array}$ & Q2PCB7 \\
\hline & TaLTP1.24 & $\begin{array}{l}\text { TaLtp9.7e (Boutrot et al. 2007); TaLtpIg.5 } \\
\text { (Boutrot et al. 2008) }\end{array}$ & Q2PCB8 \\
\hline
\end{tabular}


Table 2 continued

\begin{tabular}{|c|c|c|c|}
\hline Species & $\begin{array}{l}\text { Current name } \\
\text { (This publication) }\end{array}$ & Other names (Miscellaneous publications) & UniProt Id \\
\hline & TaLTP1.25 & TaLTP5 (Zhu et al. 2012) & J9T0L6 \\
\hline & TaLTP1.26 & $\begin{array}{l}\text { TaLt10B6 (Gaudet et al. 2003; Sun et al. } \\
\text { 2008) }\end{array}$ & Q1KMV1 \\
\hline & TaLTP1.27 & TaBs108F7 (Sun et al. 2008) & NA \\
\hline & TaLTP1.28 & $\begin{array}{l}\text { TaLt10F9; TaLt10E10 (Gaudet et al. 2003; } \\
\text { Sun et al. 2008) }\end{array}$ & Q1KMV0 \\
\hline & TaLTP1.29 & Ltp 3F1 (Kirubakaran et al. 2008) & A4GU98 \\
\hline & TaLTP2.1 & $\begin{array}{l}\text { LTP2 (Douliez et al. 2001; Pons et al. 2003); } \\
\text { TaLTP7.1a (Boutrot et al. 2007); } \\
\text { TaLtpIIa.1 (Boutrot et al. 2008) }\end{array}$ & P82900 \\
\hline & TaLTP2.2 & $\begin{array}{l}\text { TaLTP7.1b (Boutrot et al. 2007); TaLtpIIa.2 } \\
\text { (Boutrot et al. 2008) }\end{array}$ & Q2PCC3 \\
\hline & TaLTP2.3 & $\begin{array}{l}\text { TaLTP7.1c (Boutrot et al. 2007); TaLtpIIa.3 } \\
\text { (Boutrot et al. 2008) }\end{array}$ & Q2PCC7 \\
\hline & TaLTP2.4 & $\begin{array}{l}\text { TaLTP7.1e (Boutrot et al. 2007); TaLtpIIa.5 } \\
\text { (Boutrot et al. 2008) }\end{array}$ & Q2PCC5 \\
\hline & TaLTP2.5 & $\begin{array}{l}\text { TaLTP7.2a (Boutrot et al. 2007); TaLtpIIb.1 } \\
\text { (Boutrot et al. 2008) }\end{array}$ & Q5NE34 \\
\hline & TaLTPd1 & TaPR60 (Kovalchuk et al. 2009) & $\mathrm{B} 2 \mathrm{C} 4 \mathrm{~K} 0$ \\
\hline & TaLTPd2 & TaPR61 (Kovalchuk et al. 2012) & H9U3X3 \\
\hline \multirow[t]{2}{*}{ Triticum durum (durum wheat) } & TdLTPd1 & TdPR60 (Kovalchuk et al. 2009) & C7AE88 \\
\hline & TdLTPd2 & TdPR61 (Kovalchuk et al. 2012) & H9U3X2 \\
\hline \multirow[t]{2}{*}{ Hordeum vulgare (barley) } & HvLTP1.1 & $\begin{array}{l}\text { bLTP (Lerche et al. 1997); ns-LTP } \text { barley } \\
\text { (Lerche and Poulsen 1998); LTP1 } \\
\text { (Lindorff-Larsen et al. 2001) }\end{array}$ & P07597 \\
\hline & HvLTP1.2 & LTP7a2b (Hollenbach et al. 1997) & Q42848 \\
\hline \multirow[t]{6}{*}{ Nicotiana tabacum (tobacco) } & NtLTP1.1 & LTP1_1 (Da Silva et al. 2005) & Q42952 \\
\hline & NtLTP1.2 & NtLTP1 (Choi et al. 2012) & Q8LK72 \\
\hline & NtLTP1.3 & NtLTP2 (Choi et al. 2012) & E3W9R1 \\
\hline & NtLTP1.4 & NtLTP3 (Choi et al. 2012) & F2ZAM0 \\
\hline & NtLTP1.5 & NtLTP4 (Choi et al. 2012) & F2ZAM1 \\
\hline & NtLTP1.6 & $\begin{array}{l}\text { TobLTP2 (Masuta et al. 1992; Nieuwland } \\
\text { et al. 2005) }\end{array}$ & Q03461 \\
\hline Ginkgo biloba (ginkgo) & GbLTP1.1 & Gb-nsLTP1 (Sawano et al. 2008) & A9X6V0 \\
\hline \multirow[t]{3}{*}{ Vigna radiata (mungbean) } & VrLTP1.1 & Mb nsLTP1 (Lin et al. 2005) & P83434 \\
\hline & VrLTP1.2 & Vrltp1 (Liu and Lin, 2003) & Q6WAT9 \\
\hline & VrLTP1.3 & Vrltp2 (Liu and Lin, 2003) & Q6WAT8 \\
\hline Vigna unguiculata (cowpea) & VuLTP1.1 & VULTP (Carvalho et al. 2006) & NA \\
\hline Lillium longiflorum (lily) & LILTP1.1 & SCA (Park et al. 2000) & Q9SW93 \\
\hline Senecia squalidus & SsLTP1.1 & S. squalidus GO255151 (Allen et al. 2010) & NA \\
\hline $\begin{array}{l}\text { Astragalus sinicus (Chinese milk } \\
\text { vetch) }\end{array}$ & AsLTP1.1 & AsE246 (Lei et al. 2014). & Q07A25 \\
\hline \multirow[t]{4}{*}{ Coffea arabica } & CaLTP2.1 & CaLTP1a, CaLTP2 (Cotta et al. 2014) & S6FDF9 \\
\hline & CaLTP2.2 & CaLTP1b (Cotta et al. 2014) & S6EPL2 \\
\hline & CaLTP2.3 & CaLTP3b (Cotta et al. 2014) & S6FQL6 \\
\hline & CaLTP2.4 & CaLTP3a (Cotta et al. 2014) & S6DRK0 \\
\hline Capsicum аппиит L (chili pepper) & CaLTPc1 & CaMF2 (Chen et al. 2011) & F6LQG2 \\
\hline Brassica rapa & BrLTPd1 & BraLTP1, Bra011229 (Liu et al. 2014) & M4D425 \\
\hline Medicago truncatula & MsLTPd1 & MtN5 (Pii et al. 2009) & O24101 \\
\hline \multirow[t]{5}{*}{ Lens culinaris (lentil) } & LcLTP1.1 & Lc-LTP1 (Finkina et al. 2007) & A0AT28 \\
\hline & LcLTP1.2 & $\begin{array}{l}\text { Lc-LTP2 (Finkina et al. 2007); Len c } 3 \\
\quad \text { (Akkerdaas et al. 2012) }\end{array}$ & A0AT29 \\
\hline & LcLTP1.3 & Lc-LTP3 (Finkina et al. 2007) & A0AT30 \\
\hline & LcLTP1.4 & Lc-LTP4 (Finkina et al. 2007) & A0AT33 \\
\hline & LcLTP1.5 & Lc-LTP5 (Finkina et al. 2007) & A0AT31 \\
\hline
\end{tabular}


Table 2 continued

\begin{tabular}{|c|c|c|c|c|}
\hline Species & $\begin{array}{l}\text { Current name } \\
\text { (This publication) }\end{array}$ & Other names (Miscellaneous publications) & UniProt Id & \\
\hline & LcLTP1.6 & Lc-LTP6 (Finkina et al. 2007) & A0AT32 & \\
\hline Prunus persica (peach) & PpLTP1.1 & Pru p 3 (Fernández-Rivas et al. 2003) & Q9LED & \\
\hline \multirow[t]{2}{*}{ Corylus avellana (hazelnut) } & CaLTP1.1 & Cor a 8 (Offermann et al. 2015) & Q9ATH2 & \\
\hline & $\begin{array}{l}\text { Current name } \\
\text { (Edstam et al. } \\
\text { 2011) }\end{array}$ & & & Gene Id \\
\hline \multirow[t]{26}{*}{ Arabidopsis thaliana } & AtLTP1.5 & LTP1 (Arondel et al. 2000; Chae et al. 2010) & Q42589 & At2g38540 \\
\hline & AtLTP1.4 & LTP2 (Arondel et al. 2000; Chae et al. 2010) & Q9S7I3 & At2g38530 \\
\hline & AtLTP1.12 & $\begin{array}{l}\text { LTP3 (Arondel et al. 2000; Jung et al. 2003; } \\
\text { Chae et al. 2010; Guo et al. 2013b) }\end{array}$ & Q9LLR7 & At5g59320 \\
\hline & AtLTP1.11 & $\begin{array}{l}\text { LTP4 (Arondel et al. 2000; Jung et al. 2003; } \\
\text { Chae et al. 2010) }\end{array}$ & Q9LLR6 & At5g59310 \\
\hline & AtLTP1.8 & LTP5 (Arondel et al. 2000; Chae et al. 2010) & Q9XFS7 & At3g51600 \\
\hline & AtLTP1.6 & LTP6 (Arondel et al. 2000; Chae et al. 2010) & F4IXC6 & At3g08770 \\
\hline & AtLTP1.1 & LTP7 (Arondel et al. 2000; Chae et al. 2010) & Q9ZUK6 & At2g15050 \\
\hline & AtLTP1.3 & LTP8 (Arondel et al. 2000; Chae et al. 2010) & Q9ZPW9 & At2g18370 \\
\hline & AtLTP1.2 & LTP9 (Arondel et al. 2000; Chae et al. 2010) & Q6AWW0 & At2g15325 \\
\hline & AtLTP1.10 & $\begin{array}{l}\text { LTP10 (Arondel et al. 2000; Chae et al. } \\
\text { 2010) }\end{array}$ & Q9LZV9 & At5g01870 \\
\hline & AtLTP1.9 & $\begin{array}{l}\text { LTP11 (Arondel et al. 2000; Chae et al. } \\
\text { 2010) }\end{array}$ & $\mathrm{Q} 2 \mathrm{~V} 3 \mathrm{C} 1$ & AT4G33355 \\
\hline & AtLTP1.7 & $\begin{array}{l}\text { LTP12 (Arondel et al. 2000; Chae et al. } \\
\text { 2010) }\end{array}$ & Q9SCZ0 & At3g51590 \\
\hline & AtLTPd1 & DIR1 (Maldonado et al. 2002) & Q8W453 & At5g48485 \\
\hline & AtLTPd2 & DIR1-like (Champigny et al. 2013) & $\begin{array}{l}\text { Q84WQ6; } \\
\text { Q9LV65 }\end{array}$ & At5g 48490 \\
\hline & AtLTPd9 & END1 (Li et al. 2014b) & Q9LQN1 & At1g32280 \\
\hline & AtLTPd12 & END2 (Li et al. 2014b) & Q9FM83 & At5g56480 \\
\hline & $\begin{array}{l}\text { Current name } \\
\text { (Edstam et al. } \\
\text { 2013) }\end{array}$ & & & \\
\hline & AtLTPg1 & LTPG1 (Debono et al. 2009; Lee et al. 2009) & Q9C7F7 & At1g27950 \\
\hline & AtLTPg2 & LTPG2 (Kim et al. 2012) & Q9LZH5 & At3g43720 \\
\hline & AtLTPg3 & & Q9LE56 & At1g18280 \\
\hline & $\operatorname{AtLTPg} 4$ & & Q2PE70 & At4g08670 \\
\hline & AtLTPg5 & & Q9LJ86 & At3g22600 \\
\hline & AtLTPg6 & & Q9C896 & At1g55260 \\
\hline & AtLTPg23 & & Q2PE60 & At $\lg 36150$ \\
\hline & AtLTPg26 & & Q2PE59 & At4g14815 \\
\hline & $\begin{array}{l}\text { Current name } \\
\text { (Edstam et al. } \\
\text { 2013; Wei and } \\
\text { Zhong, 2014) }\end{array}$ & & & Locus name \\
\hline \multirow[t]{7}{*}{ Oryza sativa (rice) } & OsLTP1.18 & LTP (Lee et al. 1998) & Q0IQK9 & $\begin{array}{l}\text { Os12g0115100, } \\
\text { LOC_Os12g02320 }\end{array}$ \\
\hline & OsLTP2.3 & LTP-2 (Samuel et al. 2002) & Q10ST8 & $\begin{array}{l}\text { Os03g0111300, } \\
\text { LOC_Os03g02050 }\end{array}$ \\
\hline & OsLTPd11 & $\begin{array}{l}\text { OsLTP6 (Liu et al. 2013), } \\
\text { OsDIL (Guo et al. 2013a) }\end{array}$ & Q10A49; Q33B26 & $\begin{array}{l}\text { Os10g0148000, } \\
\text { LOC_Os10g05720 }\end{array}$ \\
\hline & OsLTPg 1 & & Q8RZK6 & $\begin{array}{l}\text { Os01g0814100; } \\
\text { LOC_Os01g59870 }\end{array}$ \\
\hline & OsLTPg2 & & Q10R96 & $\begin{array}{l}\text { Os03g0167000; } \\
\text { LOC_Os03g07100 }\end{array}$ \\
\hline & OsLTPg24 & & Q0D9K5 & $\begin{array}{l}\text { Os06g0711900; } \\
\text { LOC_Os06g49770 }\end{array}$ \\
\hline & OsLTPg25 & OsC6 (Zhang et al. 2010) & Q2R222 & $\begin{array}{l}\text { Os11g0582500, } \\
\text { LOC_Os11g37280 }\end{array}$ \\
\hline
\end{tabular}


Table 2 continued

\begin{tabular}{lllll}
\hline Species & $\begin{array}{l}\text { Current name } \\
\text { (This publication) }\end{array}$ & Other names (Miscellaneous publications) & UniProt Id & \\
\hline Zea mays (maize) & ZmLTP1.2 & Zm-LTP & O24583 & GRMZM2G010868 \\
& ZmLTP1.6 & LTP (Gomar et al.1996; Shin et al. 1995); & P19656 & GRMZM2G101958 \\
& Zea m 14 (Pastorello et al. 2000) & B6SHX0; C5JA67 & GRMZM2G087413 \\
& ZmLTPd6 & BETL9 (Royo et al. 2014) & B4FFB8 & GRMZM2G091054 \\
& ZmLTPd14 & BETL9like (Royo et al. 2014) & &
\end{tabular}

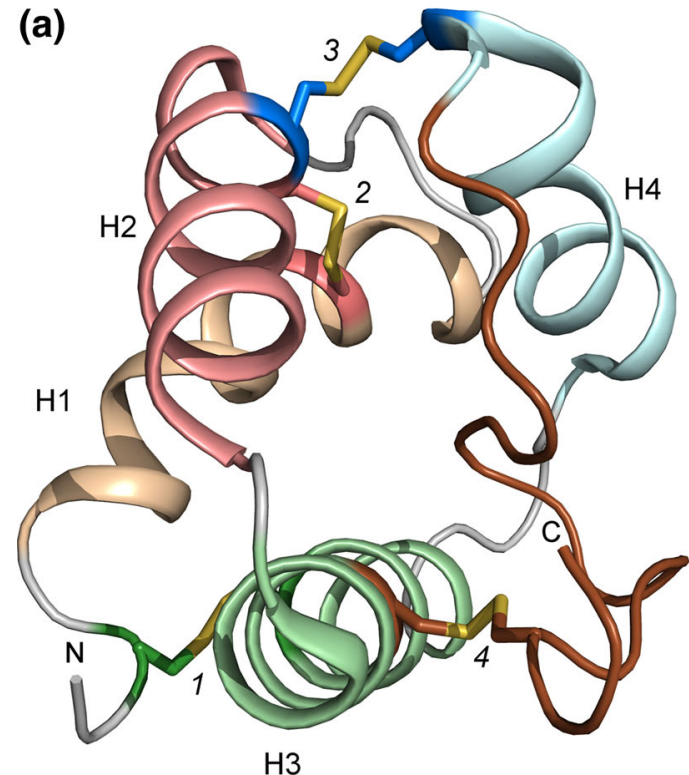

Fig. 1 The 3D structure of TaLTP1.1. a The four helices in the 3Dfold of TaLTP1.1 are stabilized by four disulfide bridges. The first bridge (1; Cys residues shown as green sticks) links the N-terminal part (N) to H3 (green), the second one (2; Cys as pink sticks) connects $\mathrm{H} 1$ (wheat) to $\mathrm{H} 2$ (pink), the third one (3; Cys as blue sticks) connects

12-anthroyloxystearate from the cavity of wheat TaLTP1.1 was investigated, an increased number of cis-double bonds in the tested $\mathrm{C} 18$ fatty acids led to a lower displacement power. A single unsaturation, though, did not affect the affinity of the fatty acid for the protein (Guerbette et al. 1999a).

Many lyso-PC (LPC) or lyso-PG (LPG) derivatives (Table 3) have been used for investigating the ligand binding of LTPs. In all the LPC or LPG derivatives, only one fatty acyl chain is connected to the PC or PG backbone. The 2.1- $\AA$ crystal structure of TaLTP1.1:LMPC (Charvolin et al. 1999; PDB ID 2BWO) showed that TaLTP1.1 can accommodate two molecules of LMPC (Fig. 2b; Table 3). The two lipids are positioned head to tail. The aliphatic chains are positioned inside the cavity, while the polar head groups are directed toward the solvent areas, at each end of the tunnel. In site 1, LMPC contacts (b)

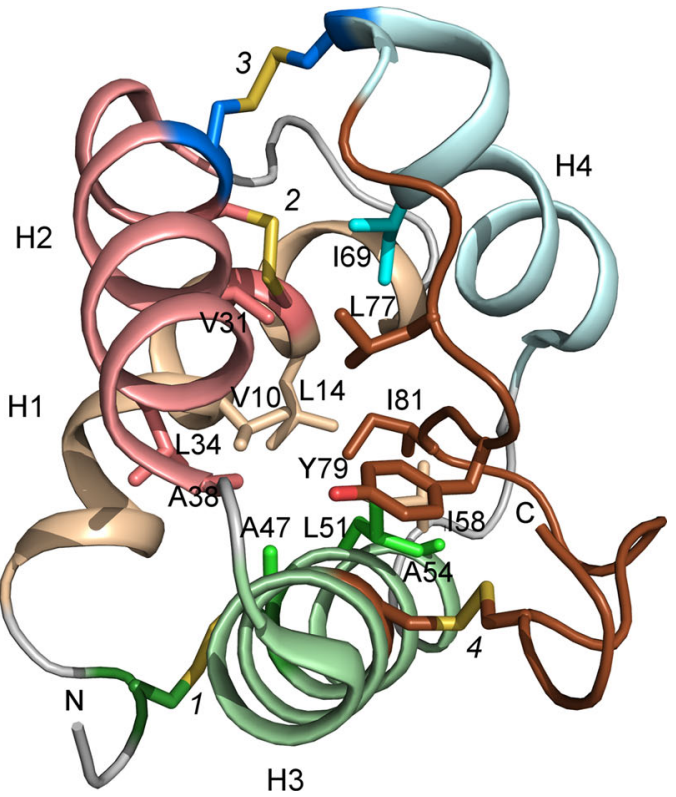

$\mathrm{H} 2$ (pink) to $\mathrm{H} 4$ (pale cyan), and the last disulfides bridge (4; Cys as brown sticks) binds the $\mathrm{C}$-terminal part $(\mathrm{C}$; brown $)$ to $\mathrm{H} 3$. b The internal cavity of TaLTP1.1 is formed by residues from each of the helices. The residues lining the cavity are shown as sticks and colored similarly as the helices

wheat TaLTP1.1 via hydrophobic interactions and through a hydrogen bond with the side chain hydroxyl of Tyr79, whereas in site 2, LMPC is only involved in a few hydrophobic interactions (Fig. 2b).

TaLTP1.1 has also been crystallized binding to the fatty acid derivative prostaglandin $\mathrm{B} 2\left(\mathrm{PGB}_{2}\right)$ (Table 3) (TassinMoindrot et al. 2000). Prostaglandins are a subclass of the biologically active lipid mediators known as eicosanoids. These lipids have diverse hormone-like effects in animals. Prostaglandins are enzymatically formed from arachidonic acid, a 20-carbon unsaturated fatty acid with four cisdouble bonds. In the prostaglandins, the carbon skeleton always contains a 5-carbon ring. The Leu77-Ile85 segment of the C-terminal part, in which the unliganded form makes contact with the $\mathrm{H} 4$ helix, moves outward in the solution structure of the TaLTP1.1:PGB 2 complex [Fig. 2a, c; Tassin-Moindrot et al. (2000); (PDB ID 1CZ2)]. After 
Table 3 List of LTP 3D structures

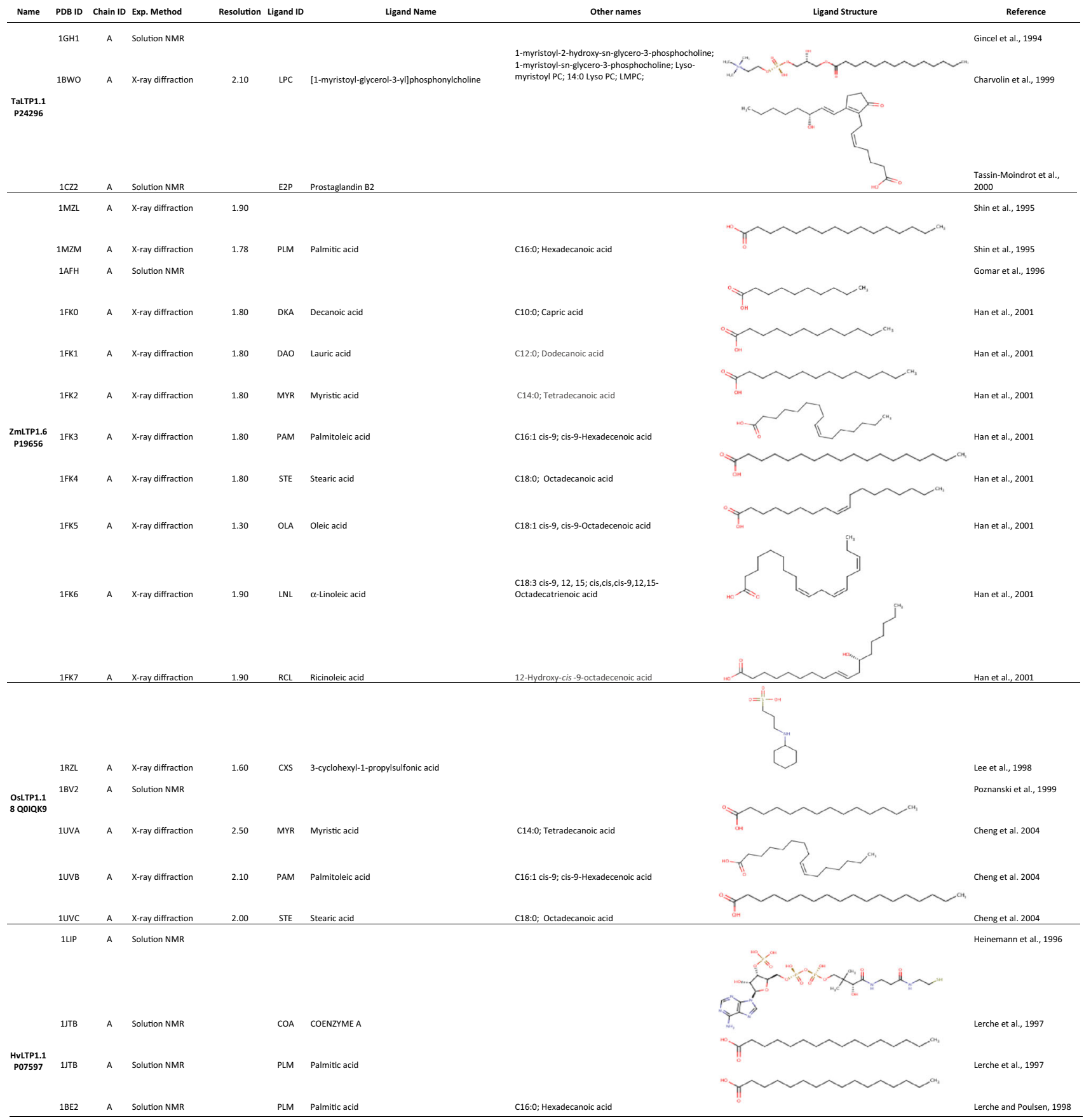


Table 3 continued

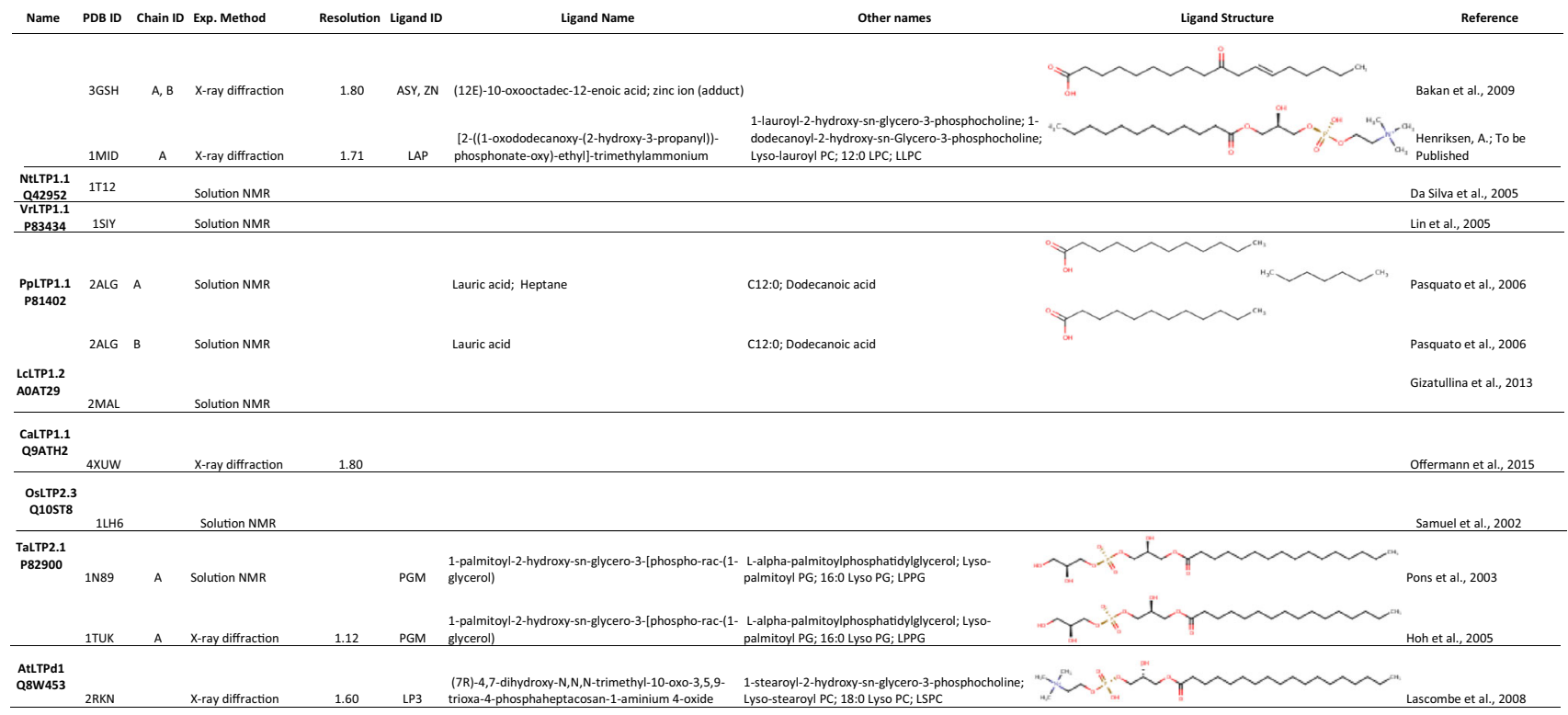

binding $\mathrm{PGB}_{2}$, the volume of the cavity in wheat TaLTP1.1 increases from $300 \pm 50 \AA^{3}$ in the unliganded protein to $786 \pm 43 \AA^{3}$. The size of the cavity is thus comparable to the TaLTP1.1:DMPG complex. However, Tyr79 has an important role in the binding of $\mathrm{PGB}_{2}$. The interaction induces a $100^{\circ}$ rotation around the $\mathrm{C} \beta-\mathrm{C} \gamma$ bond of the Tyr79 ring. This rotation facilitates that a hydrogen bond is formed between the carboxyl group of the ligand and the hydroxyl group of Tyr79 (Fig. 2a, c). In addition, several hydrophobic residues lining the internal cavity are pushed away by the ligand (Tassin-Moindrot et al. 2000). The most drastic conformational change is probably seen for Ile81, in order to avoid unfavorable contacts with the hydroxyl group of the aliphatic chain of $\mathrm{PGB}_{2}$ (Fig. 2a, c). The comparisons of these TaLTP1.1 structures show clearly that Leu77, Tyr79, and Ile81 in the C-terminal part adopt their conformation and position depending on the size and chemical nature of the ligand (Fig. 2d).

Another approach for studying lipid:protein interactions is to monitor the change in intrinsic fluorescence of tyrosine residues in the protein after addition of a lipid ligand (Douliez et al. 2000). According to such experiments on wheat TaLTP1.1, the dissociation constant and stoichiometry were fairly constant from $\mathrm{C} 14$ to $\mathrm{C} 18$ chain lengths with a $K_{\mathrm{d}}$ between 0.3 to $0.7 \mu \mathrm{M}$ and approximately 1.7 bound ligands per protein (Douliez et al. 2000). Furthermore, the affinities of wheat LTP1 for cis- or trans-unsaturated $\mathrm{C} 18$ fatty acids were quite similar to the affinity for the saturated stearic acid.

\section{Maize LTP1}

The first high-resolution crystal structure of any plant LTP1 was published 1995, when the 3D structures of unliganded and palmitate-bound maize ZmLTP1.6 were determined at $1.9 \AA$ (PDB ID 1MZL) and $1.8 \AA$ (PDB ID 1MZM) resolution, respectively (Shin et al. 1995) (Table 3). Similar to wheat TaLTP1.1, in maize ZmLTP1.6 both the $\mathrm{N}$-terminal and $\mathrm{C}$-terminal regions are linked to the long helix H3, by a pair of disulfide bonds, namely, Cys4-Cys52 and Cys50-Cys89. The other pairs Cys14Cys 29 and Cys30-Cys75 link the ends of helices H1B and $\mathrm{H} 4$ to the N-terminus of another long helix, H2 (Fig. 3a; dark violet). The volume of the hydrophobic cavity, which runs through the protein, was estimated to $300 \AA^{3}$. One end of the tunnel, near Ala40, has an opening of $5 \AA$ in diameter, while the other end of the tunnel, near Ala18, has a narrower opening with a diameter of $3 \AA$. There are polar and charged residues in the vicinity of the larger opening, while only non-polar residues nearby the smaller opening (Fig. 3a).

In the ZmLTP1.6:palmitic acid complex, there are structural changes in the C-terminal region that result in a slight swelling of the cavity (Fig. 3a). The residues Ile11, Ile79, Tyr81, and Ile83 are displaced from the hydrophobic cavity to let the palmitate acyl-chain fit inside the cavity, while its carboxyl group forms a hydrogen bond with the hydroxyl group of Tyr81. Apart from these changes, the overall fold of the complex is identical to the uncomplexed 
(a)

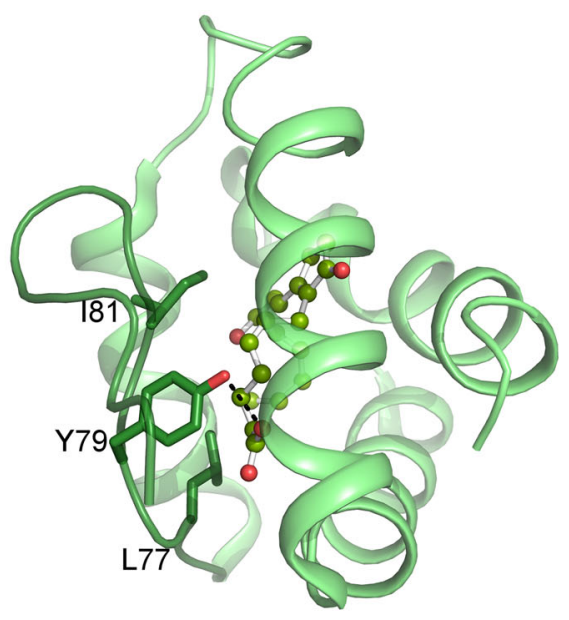

(c)

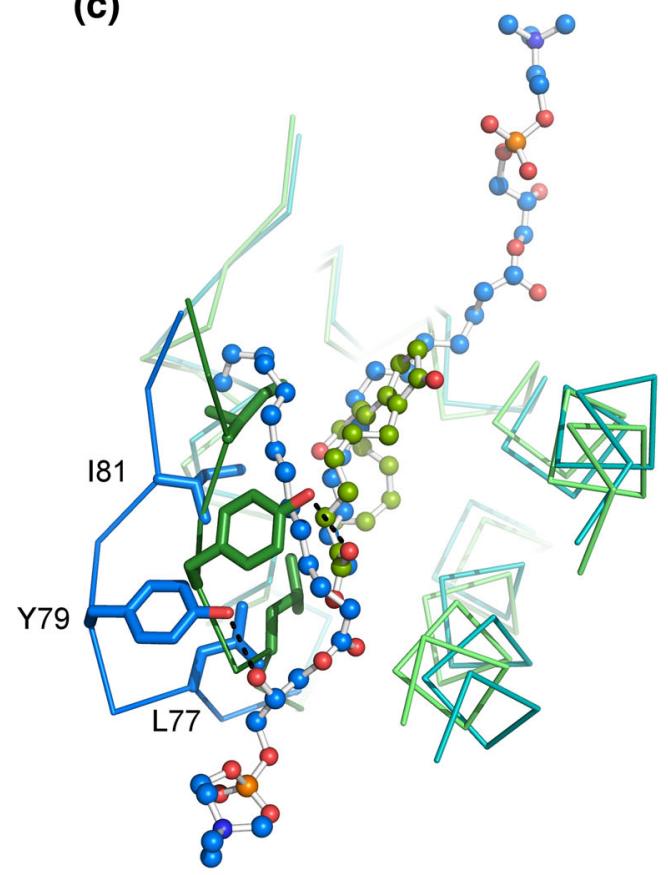

Fig. 2 Ligand-binding properties of TaLTP1.1. The hydrogen bonds formed by Tyr79 and the ligands are shown with dashed line. a-c are in the same orientation. a The TaLTP1.1:PGB ${ }_{2}$ complex. b The TaLTP1.1:LMPC complex. c The structural differences between the $\mathrm{PGB}_{2}$ and LMPC complexes. d A comparison of unliganded

structure. Furthermore, only one acyl chain could fit into the cavity of the maize ZmLTP1.6 according to Shin et al. (1995). Binding of another chain would mean that the second one has to extend into the solvent.

The 3D solution structure of ZmLTP1.6 (Gomar et al. 1996; PDB ID 1AFH) was published shortly after the

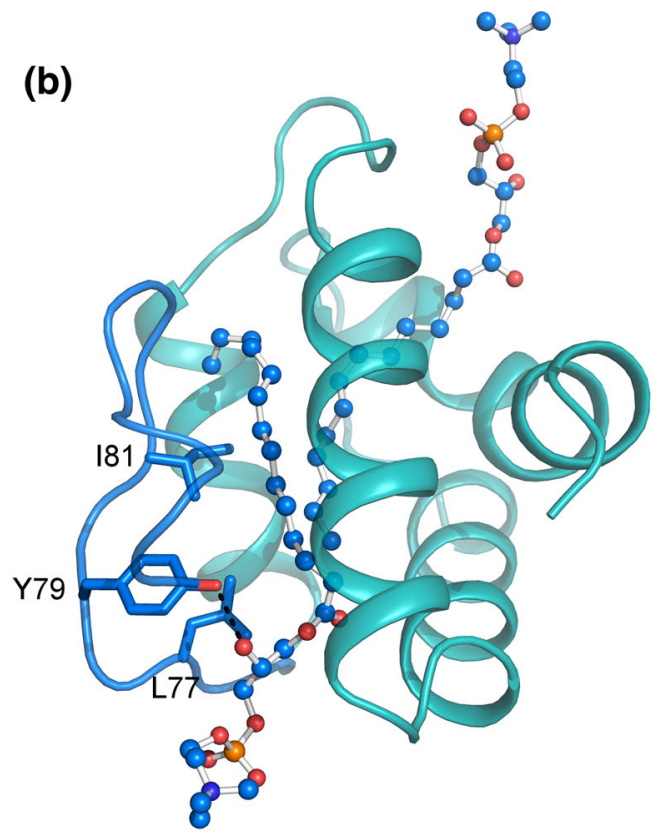

(d)

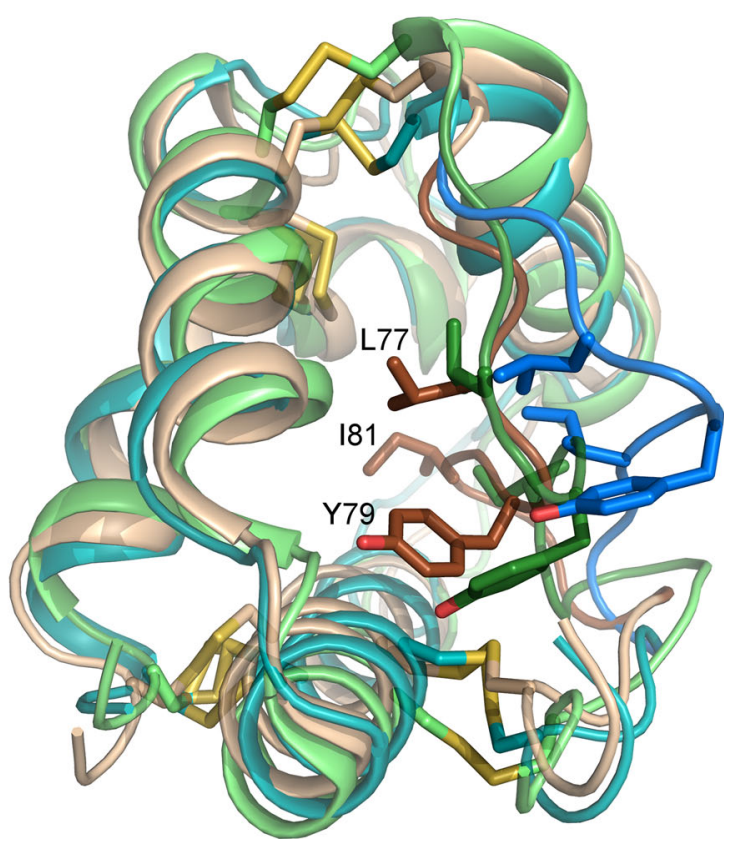

TaLTP1.1 (wheat) with the ligand bound forms (green and blue). The comparison shows clearly that the C-terminal part with residues Leu77, Tyr79, and Ile81 (residues 75-84 in darker color) makes major movements depending on the size of the ligand

publication of the 3D crystal structure. The solution and crystal structures showed good correlation with clear differences only in the C-terminal region (Fig. 3b). Comparison of the solution structures of TaLTP1.1 and ZmLTP1.6 revealed differences in helices $\mathrm{H} 1$ and $\mathrm{H} 4$ (Fig. 3c). H1 is somewhat longer in ZmLTP1.6, while 

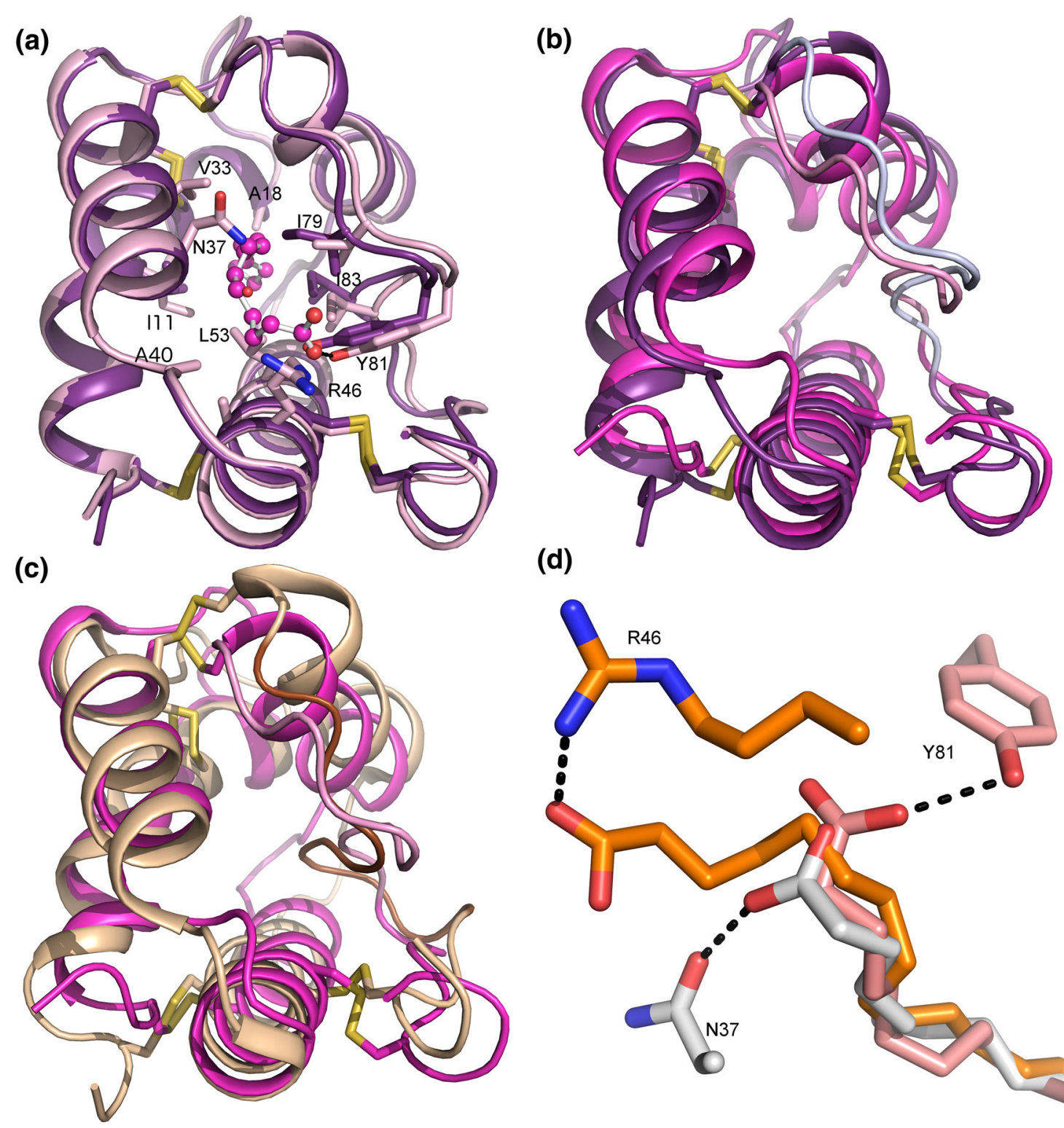

(d)

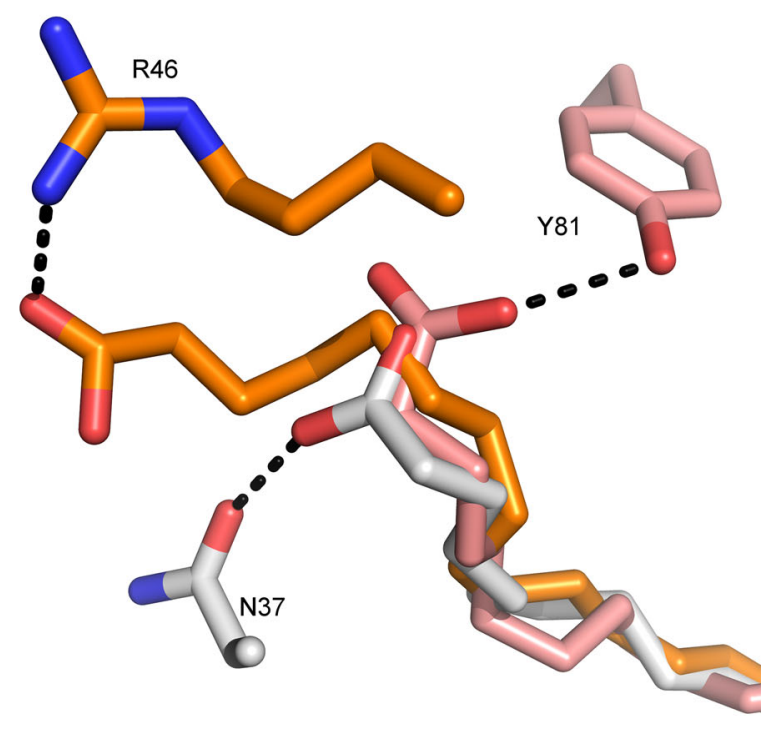

Fig. 3 The 3D structure of ZmLTP1.6. a ZmLTP1.6 without ligand (dark violet) and with palmitic acid (light pink; palmitic acid shown as pink ball-and-stick). Residues that change their position most are shown as sticks. b The NMR (magenta) and X-ray (dark violet) unliganded structures of ZmLTP1.6. Differences between the structures are mainly located to the C-terminal region (residues 75-84 shown with lighter colors). c The NMR structures of ZmLTP1.6

H4 in TaLTP1.1 is disrupted by two consecutive prolines.

Incubation of maize ZmLTP1.6 with 16(9-anthroyloxy)palmitate either alone or together with another fluorescent fatty acid analog, P-96, revealed that the binding cavity of ZmLTP1.6 can accommodate two fatty acids simultaneously (Zachowski et al. 1998). Further competition experiments with anthroyloxy-fatty acid analogs showed that fatty acids of 16-19 carbons were the preferred ligands. Fatty acyl-CoA or LPC derivatives bound as

(magenta) and TaLTP1.1 (wheat and brown). Obvious differences between the structures are found in the positions of helices $\mathrm{H} 1$ and $\mathrm{H} 4$, the loops, and the C-terminal region. $\mathbf{d}$ The fatty acid binding properties of ZmLTP1.6. The carboxyl groups of oleic acid (orange), myristic acid (white), and palmitoleic acid (pink) form a hydrogen bond with Arg46 (orange), Asn37 (white), and Tyr81 (pink), respectively

well as the corresponding fatty acids. The presence of one double bond did not change appreciably the affinity of ZmLTP1.6, while the presence of two or three double bonds or of a hydroxyl moiety significantly reduced the affinity.

Lipid transfer assays, where the transfer of labeled lipids from quenched donor vesicles to unquenched acceptor vesicles is measured, are also frequently used to investigate the properties of LTPs (Edqvist et al. 2004; Lin et al. 2005). When LTPs from wheat and maize seeds were 
compared in in vitro transfer assays, maize LTP had higher transfer activity and showed faster kinetics for fatty acid binding (Guerbette et al. 1999a, b).

ZmLTP1.6 was later crystallized with fatty acids of different chain lengths, from capric acid (C10:0) to stearic acid (C18:0) to investigate how the chain length would influence the interactions between protein and lipid (Han et al. 2001) (Table 3). The cavity volume of ZmLTP1.6 increases only slightly, from 558 to $582 \AA^{3}$, when the length of the complexed fatty acid increases from $\mathrm{C} 10$ to C18. Furthermore, cis-unsaturated $\mathrm{C} 18$ fatty acid chains with double bonds in cis configuration, such as oleic acid (C18:1), linoleic acid (C18:2), and linolenic acid (C18:3), were also used as ligands during crystallization. Double bonds in cis configuration enforce a more curved shape on the fatty acid compared with the saturated fatty acids which are linearly shaped. On the other hand, fatty acids with double bonds in trans-configuration are linear and more similar to the saturated fatty acids. Therefore, the LTPs could possibly show different binding modes or affinities for saturated, cis- or trans-fatty acids. The maize ZmLTP1.6 was also crystallized with the hydroxylated, cis-unsaturated $\mathrm{C} 18$ fatty acid 12-hydroxy-9-cis-octadecenoic acid (ricinoleic acid). The double bond and the hydroxyl group give the ricinoleic acid a more bulky shape compared to the other more common $\mathrm{C} 18$ fatty acids. Ricinoleic acid is the major component of the seed oil obtained from Ricinus communis L. (castor oil plant).

The crystals of the ZmLTP1.6:ligand complexes revealed that the cavity volume somewhat depends on the shape of the $\mathrm{C} 18$ fatty acid, expanding from $557 \AA^{3}$ for stearic acid up to $620 \AA^{3}$ for ricinoleic acid (Han et al. 2001). This implies that there is a requirement for lipiddependent plasticity in the shape of the cavity. In several of the ZmLTP1.6:ligand complexes, the ligands bind favorably into the cavity in only one of two possible directions due to the interactions with Tyr81, Arg46, and Asn37 (Fig. 3d). These residues are located along the top opening of the cavity and interact with the carboxylate group of most ligands. For instance, the carboxyl group of the shorter fatty acids, lauric acid (C12:0; PDB ID 1FK1), and myristic acid (C14:0, PDB ID 1FK2) (Table 3) forms a hydrogen bond with the side chain of Asn37, whereas the carboxyl group of the longer $\mathrm{C} 16$ fatty acids, palmitic acid (C16:0; PDB ID 1MZM), and palmitoleic acid (C16:1; PDB ID 1FK3) forms a hydrogen bond with the hydroxyl group of Tyr81 (Fig. 3d). However, the ZmLTP1.6 complexes with capric acid (C10; PDB ID 1FK0) and oleic acid (C18:1; PDB ID 1FK3) have two different conformations where the carboxylate group of the fatty acids is located either close to the top or to the bottom opening of the cavity (Han et al. 2001). In conformation 1 of the ZmLTP1.6:oleic acid complex, the $\mathrm{O} 1$ atom of the oleate carboxylate group forms a hydrogen bond with the $\mathrm{NH} 2$ group of Arg46 (Fig. 3d), and the $\mathrm{O} 2$ atom of the carboxylate group donates the proton to the main chain oxygen atom of either Asn40 or Ala37. In the ZmLTP1.6:oleic acid complex conformation 2, the $\mathrm{O} 1$ and $\mathrm{O} 2$ atoms of the carboxyl group in oleate interact with the hydroxyl group of Tyr81. On the other hand, the carboxylate group of capric acid does not form any hydrogen bonds with ZmLTP1.6.

Several LTP1s, such as those from Arabidopsis, cabbage, and maize, have been shown to bind with calmodulin, which is a ubiquitous $\mathrm{Ca}^{2+}$-binding protein ( $\mathrm{Li}$ et al. 2008; Shang et al. 1991; Wang et al. 2005). When interacting with maize ZmLTP1.2, calmodulin seems to inhibit the lipid binding activity of LTP according to the result from an assay based on binding to P-96 ( $\mathrm{Li}$ et al. 2008). Curiously, calmodulin has the opposite effect on the Brassica rapa subsp. Pekinensis (chinese cabbage) BrLTP1.9 (BP-10), as binding to calmodulin enhances its P-96 binding activity.

\section{Rice LTP1}

The crystal structure of unliganded rice OsLTP1.18 at $1.6 \AA$ resolution (PDB ID 1RZL) showed a fold very similar to maize ZmLTP1.6 (Lee et al. 1998). Anyway, two regions with clear differences can be identified. First, the deletion of Gln21 in ZmLTP1.6 results in a large displacement of the residues 19-22 in the loop between H1 and H2. Second, in OsLTP1.18, the C-terminal loop around Tyr79 is collapsed into the hydrophobic cavity, which leads to a considerably smaller cavity, calculated to $144 \AA^{3}$ for OsLTP1.18 (Lee et al. 1998). In both the X-ray and the NMR structures of OsLTP1.18 (PDB ID 2BV2; Poznanski et al. 1999), the side-chain of Arg44 swings down toward the cavity and partially plugs the opening. The side-chain of Ile81 terminates the other end of the cavity, while the side-chain of Tyr79 divides the cavity into two parts.

The X-ray structures of OsLTP1.18 in complex with myristic acid (PDB ID 1UVA), palmitic acid ((PDB ID 1UVB), and stearic acid (PDB ID 1UVC) (Table 3) revealed that the ligand binding required a noteworthy swelling of the cavity. During the ligand binding, Arg44 moves away from the cavity, and it is, therefore, not involved in forming hydrogen bonds. Rather, Arg44 acts as a gate keeper giving the lipids access to the tunnel. Similarly, Tyr79 moves away from the lipid to create a binding site in the cavity. The distances between the hydroxyl group of Tyr79 and the carboxyl group of lipid, thereby, become too large to enable the formation of hydrogen bonds (Fig. 4). Rather than interacting with the protein, both myristic acid and palmitic acid interact with water molecules surrounding the protein (Cheng et al. 2004b). 


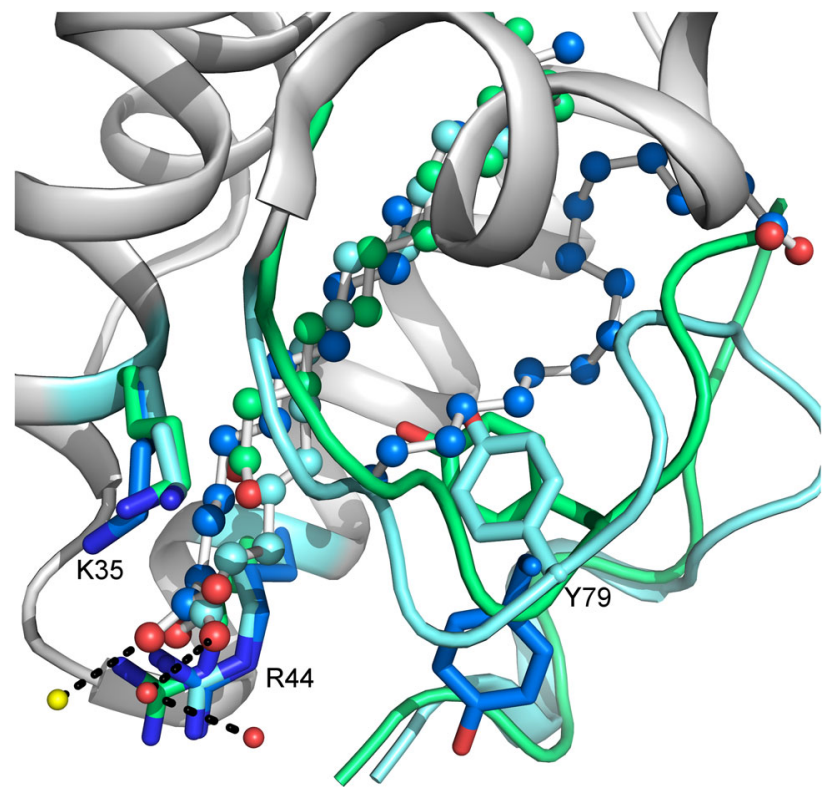

Fig. 4 OsLTP1.18 in complex with myristate (cyan), two palmitates (blue), and stearate (green). Tyr79 swings away from the lipid binding cavity when the protein accommodates the second palmitate molecule. Lys35 and Arg44 create a positively charge environment in the cavity opening, but they are not involved in direct hydrogen bonds with the lipids. Similarly, the carboxyl group of stearate is nearby Tyr79, but the bonding distance is too long for a hydrogen bond. The C-terminal region (green) adopts slightly different conformation in the stearate complex compared with the two other complexes (cyan). Both myristate and palmitate interact with water molecules that surround the protein. The water molecules involved in myristate binding are shown as red spheres and the one interacting with palmitate as a yellow sphere

\section{Barley LTP1}

Acyl-coenzyme As (acyl-CoAs) are coenzymes where fatty acid is linked to the terminal thiol moiety of CoA. The acyl-CoAs are commonly involved in metabolism of fatty acids and other lipids, such as in $\beta$-oxidation and glycerolipid synthesis. Several acyl-CoAs have been used in the crystallization and specificity studies of the LTPs. For instance, barley HvLTP1.1 was crystallized in a complex with palmitoyl-CoA (PCoA) (Lerche et al. 1997). The solution structures of the uncomplexed barley HvLTP1.1 (PDB ID 1LIP; Heinemann et al. (1996) and the HvLTP1.1:PCoA complex (PDB ID 1JTP; GI:157830246) unveiled a major conformational change in the protein upon ligand-binding (Lerche et al. 1997). The cavity volumes were calculated to $39 \AA^{3}$ for the uncomplexed HvLTP1.1 and $620 \AA^{3}$ for the LTP:PCoA complex (Lee et al. 1998). This expansion of the cavity is obtained by a bend in helix $\mathrm{H} 1$ and by conformational changes in both the C-terminus and helix H3 (Fig. 5a). The palmitoyl chain of PCoA is completely buried in the hydrophobic cavity, where it is bent in a U-shape. Met10, in H1, and Tyr79, in the C-terminal part, are two key residues that interact with each end of the palmitoyl chain.

The binding of palmitic acid causes much less of structural alterations in HvLTP1.1. In this case, the protein undergoes significant structural perturbations only in the C-terminal residues (Lerche and Poulsen 1998). The modes for binding palmitic acid are different between maize ZmLTP1.6 and HvLTP1.1. In the ZmLTP1.6 complex, the carboxyl end of palmitic acid is in close vicinity to Arg44 and Tyr79, and the methyl group makes contacts to the hydrophobic residues in the second half of $\mathrm{H} 1$ and $\mathrm{H} 4$. In the HvLTP1.1:palmitate complex, the fatty acid is oriented in the completely opposite direction (Fig. 5b). Molecular simulations suggest that a range of small sequence differences in the $\mathrm{H} 1-\mathrm{H} 2$ loop, connecting $\mathrm{H} 1$ and $\mathrm{H} 2$ at the base of the hydrophobic cavity, and in $\mathrm{H} 1$ contribute to the different binding modes in barley HvLTP1.1 and maize ZmLTP1.6 (Smith et al. 2013).

The intrinsic fluorescence of tyrosine was used to probe the binding of lipids to HvLTP1.1. However, at first, the solvent exposed Tyr91 had to be removed from HvLTP1.1 by cleavage with carboxypeptidase. The $\mathrm{K}_{\mathrm{d}}$ for binding to LMPC for this truncated form of HvLTP1.1 was close to $10^{-6} \mathrm{M}$ (Douliez et al. 2001), which is similar to the $K_{\mathrm{d}}$ reported for wheat TaLTP1.1 (Douliez et al. 2000). HvLTP1.1 was also shown to bind to $\omega$-hydroxypalmitate with a $K_{\mathrm{d}}$ comparable to what was found for LMPC. Titrations with LMPC further revealed that barley HvLTP1.1 could bind two LMPC molecules simultaneously (Douliez et al. 2001).

An abundant form of LTP1, named LTP1b, with a covalently bound adduct in the form of an $\alpha$-ketol has been identified in barley and wheat seeds (Perrocheau et al. 2006; Douliez et al. 2001). The $\alpha$-ketol adduction enhances the lipid transfer activity of both the wheat and barley LTP1s, as revealed in a transfer assay using donor vesicles containing pyrene-PG. In the crystal structure of barley HvLTP1b (PDB ID 3GSH), the $\alpha$-ketol is partly exposed at the surface of the protein and partly buried in the hydrophobic cavity (Bakan et al. 2006).

\section{Other LTP1}

Tobacco NtLTP1.1 was produced in Pichia pastoris from a cDNA isolated from the shoot apex of tobacco, and its 3D structure was investigated with NMR spectroscopy (Da Silva et al. 2005). The global fold of the NtLTP1.1 (PDB ID 1T12) is very similar to that of cereal seed LTP1. The cavity volume of NtLTP1.1 was calculated to $318 \AA^{3}$. The binding properties of NtLTP1.1 were analyzed by following the chemical shift variations of NMR signals upon lipid binding. These measurements indicated that only one LMPC molecule could fit into the hydrophobic cavity. 
(a)

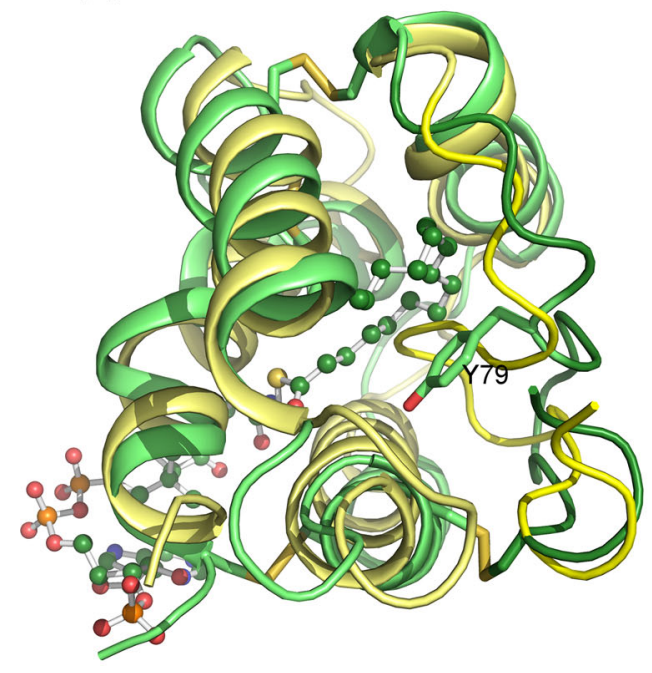

(b)

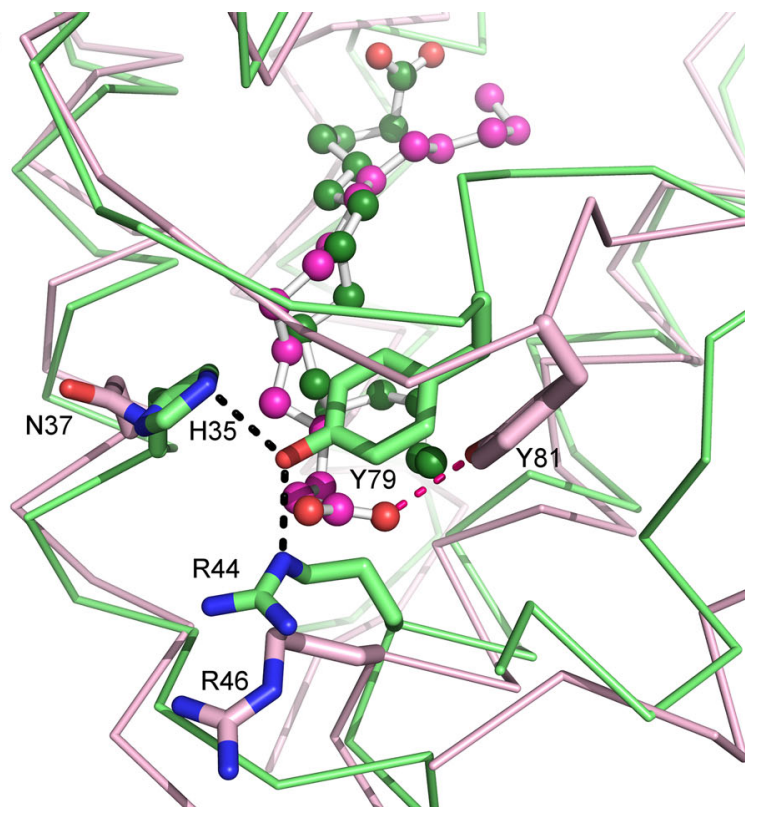

group of the palmitate (shown as green ball-and-sticks) does not interact with Tyr79. Instead, Tyr79, Arg44 and His35 form hydrogen bonds with each and close the cavity opening. The orientation of palmitate is opposite to that in the ZmLTP1.6 complex (violet, palmitate shown in magenta) where palmitate interacts with Tyr81 (red bond)

acids, such as palmitoleic acid, oleic acid, linoleic acid, and linolenic acid, could displace TNS from the binding cavity in the Ginkgo LTP1. In contrast, saturated fatty acids (C8:0-C18:0) and the trans-unsaturated elaidic acid could not compete with TNS (Sawano et al. 2008).

The Vigna radiata (mung bean) VrLTP1.1 was purified from seeds, and its 3D structure was determined by solution NMR spectroscopy (PDB ID 1SIY). Comparison of VrLTP1.1 and rice OsLTP1.18 showed that conformational changes of the C-terminal loop of VrLTP1.1 result in a larger hydrophobic cavity volume. The volume of the hydrophobic cavity in VrLTP1.1 is $510 \pm 45 \AA^{3}$, while it is only $330 \pm 44 \AA^{3}$ for rice OsLTP1.18. Nevertheless, VrLTP1.1 and OsLTP1.18 showed very similar activities when tested in a lipid transfer assay based on monitoring the increase in fluorescence resulting from the transfer of pyrene-PC from quenched donor vesicles to unquenched acceptor vesicles (Lin et al. 2005).

Prunus persica (peach) PpLTP1.1 (Pru p 3) was crystallized in complex with a ligand, presumably a fatty acid resembling laurate originating from the heterologous production in E. coli (Pasquato et al. 2006; (PDB ID 2ALG; PDB ID 2B5S). Two molecules of PpLTP1.1 were found that bound the ligand in different ways. One molecule (Molecule A) is the fully liganded protein, while the other molecule (Molecule B) represents a partially ligated state. The most significant difference between the molecules is 
found in two regions formed by residues 52-58 and 76-85, respectively. The former corresponds to the final part of the $\alpha$-helix 3 and the loop connecting it to helix 4 , and the latter is close to the C-terminus. In Molecule $\mathrm{B}$, the latter region collapses toward the core of the molecules leading to a reduction in the size of the cavity. Tyr79 is playing a significant role, as its side-chain is on the external surface in the case of Molecule $\mathrm{A}$ and points toward the interior cavity in Molecule B, occupying part of the space of ligand bound in molecule A. In barley HvLTP1.1 complexed with a ligand, Tyr79 is oriented as in Molecule A, while in liganded wheat TaLTP1.1, rice OsLTP1.18, and maize ZmLTP1.6, the Tyr79 points toward the interior of the cavity as in Molecule B.

Superpositioning of the liganded PpLTP1.1 with the crystal structure of the unliganded Corylus avellana (hazelnut) CaLTP1.1 (Cor a 8) revealed striking differences in the binding pocket. In the liganded PpLTP1.1, lauric acid occupies the binding cavity, whereas in the unliganded CaLTP1.1, the cavity is occupied by Tyr103 (corresponding to Tyr79 of PpLTP1.1) (PDB ID 4XUW; Offermann et al. 2015).

The Lens culinaris (lentil) LcLTP1.2 (Lc-LTP2) was produced as a thioredoxin fusion in E. coli, and its 3D structure in solution was obtained with NMR (PDB ID 2MAL; Gizatullina et al. 2013). LcLTP1.2 resembles other LTP1s with four helices surrounding a hydrophobic cavity. In the unliganded state, the LcLTP1.2 holds a rather large cavity with a volume of approximately $600 \AA^{3}$. NMR spectroscopy revealed that upon binding to DMPG the cavity expands to enable the accommodation of the double chained lipid. Interestingly, the DMPG:Lc-LTP2 complex have only rather limited lifetime with a half-life of about $40 \mathrm{~h}$.

\section{Rice LTP2}

The solution structure of OsLTP2.3 purified from rice flour was published in 2002 (PDB ID 1LH6; Samuel et al. 2002). The 3D-fold of OsLTP2.3 consists of five $\alpha$-helices and, similar to LTP1, eight cysteines form four disulfide bonds to stabilize the structure. In OsLTP2.3, the pairing occurs between the cysteines Cys13-Cys35, Cys11-Cys25, Cys26-Cys61, and Cys37-Cys68. Thus, the disulfide bridges are formed between $C^{1}-C^{5}, C^{2}-C^{3}, C^{4}-C^{7}$, and $C^{6}-$ $\mathrm{C}^{8}$ of the $8 \mathrm{CM}$ in LTP2, whereas in LPT1, $\mathrm{C}^{6}$ is paired with $\mathrm{C}^{1}$ and $\mathrm{C}^{5}$ with $\mathrm{C}^{8}$. Therefore, the first and fourth bridges differ between LTP1 and LTP2. Furthermore, between the 3D structures of rice OsLTP2.3 and OsLTP1.18, there is a major difference in the position of residue $\mathrm{X}$ in $\mathrm{C}^{5} \mathrm{XC}^{6}$ of the $8 \mathrm{CM}$. In rice OsLTP2.3, this residue is a hydrophobic Phe buried inside the protein (Fig. 6a), whereas in rice OsLTP1.18, the corresponding polar Asn is projected toward the surface of the protein (PDB ID 2BV2; Poznanski et al. 1999) (Fig. 6b). This difference may in part explain the different shapes of the hydrophobic cavities in OsLTP2.3 and OsLTP1.18. Samuel et al. (2002) described the shape of the OsLTP2.3 cavity as

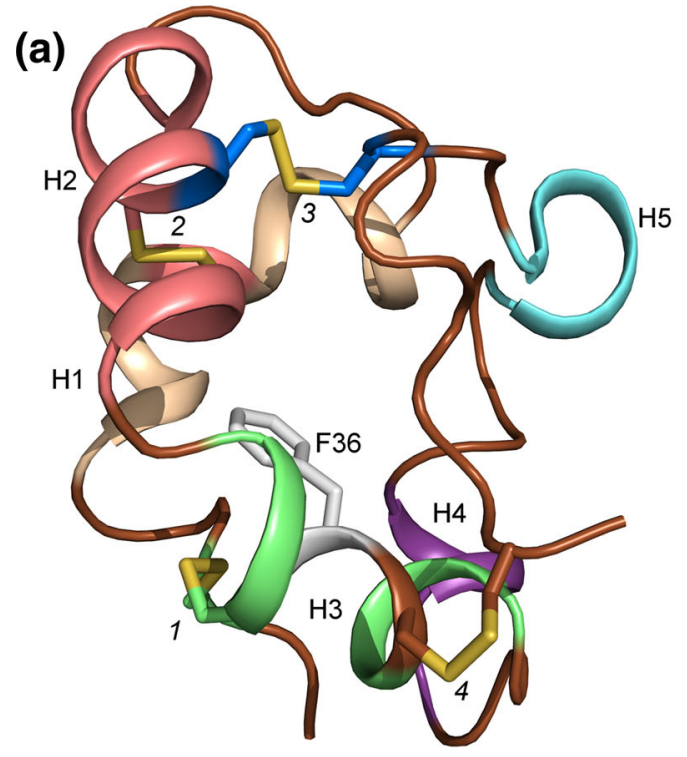

Fig. 6 Comparison of the 3D structures of rice LTP2 (OsLTP2.3) and LTP1 (OsLTP1.18). a The NMR structure of rice OsLTP2.3. The first and fourth disulfide bridges differ from LTP1 and are formed between $\mathrm{C}^{1}-\mathrm{C}^{5}$ and $\mathrm{C}^{6}-\mathrm{C}^{8}$. Due to this difference, Phe36 (white

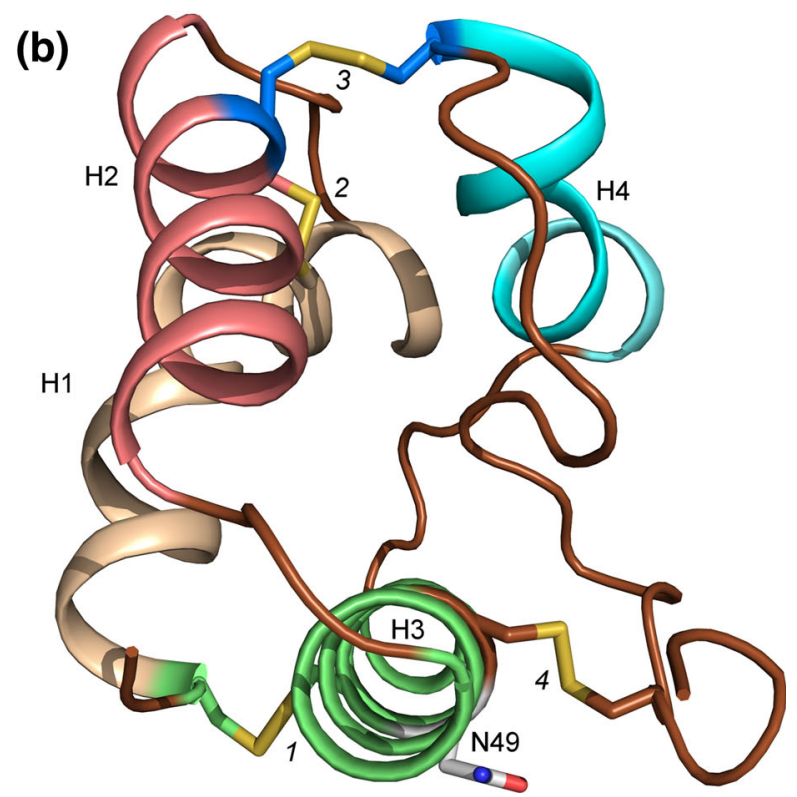

sticks) in the $\mathrm{C}^{5} \mathrm{XC}^{6}$ motif points to the ligand binding cavity. b The NMR structure of rice OsLTP1.18. The four disulfide bridges formed by $C^{1}-C^{6}, C^{2}-C^{3}, C^{4}-C^{7}$, and $C^{5}-C^{8}$ are labeled. Asn49 (white sticks) in the $\mathrm{C}^{5} \mathrm{XC}^{6}$ motif is located on the surface 
a triangular hollow box, while the shape is more tunnel-like in LTP1. The volume of the cavity in OsLTP2.3 was measured to be $140 \AA^{3}$ and, thus, somewhat smaller than in most LTP1s. Molecular modeling suggested a high degree of flexibility concerning the size and shape of the cavity, such that the binding of one molecule of stearate would increase the cavity volume to $825 \AA^{3}$.

OsLTP2.3 efficiently transfers lipid molecules between vesicles despite its smaller cavity (Samuel et al. 2002). Interestingly, rice OsLTP2.3, but not rice OsLTP1.18, binds to dehydroergosterol (DHE), a cholesterol analog with intrinsic fluorescence (Cheng et al. 2004a). The $K_{\mathrm{d}}$ for binding to DHE by rice LTP2 was measured to $71 \mu \mathrm{M}$. Tyr45 at the opening of the cavity seems to be critical for the lipid binding and transfer in OsLTP2.3. A Tyr45Ala mutant has similar 3D structure as the wild-type (WT) protein. However, it has a severely reduced capacity for binding to LMPC and DHE and also a lowered activity compared to the WT protein in lipid transfer assays (Cheng et al. 2008). Docking analysis indicated that Tyr45 directly interacts with LMPC as well as being involved in hydrophobic interactions with several carbon atoms in residues 39, 42, 44, 46, and 49. Other residues in OsLTP2.3 important for lipid binding are Ile 15 and Tyr48, which both are located at the opening of the cavity. Ile15 may be involved in controlling the entry of the sterol to the cavity, while Tyr48 is important for planar sterol binding (Cheng et al. 2008).

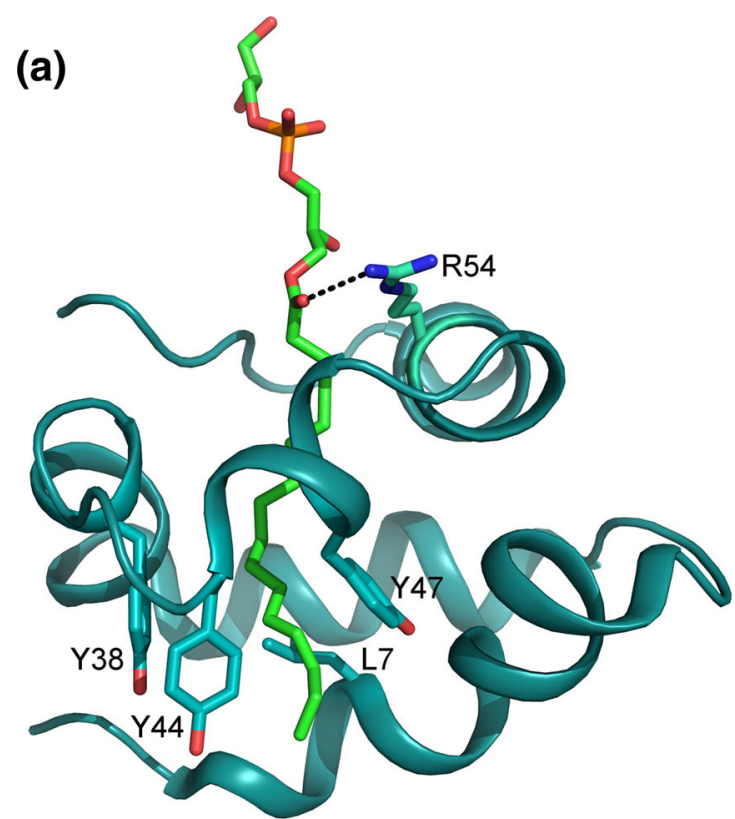

Fig. 7 3D structure of the wheat LTP2 TaLTP2.1. a The NMR structure of TaLTP2.1 (cyan) in complex with LPPG (shown as green sticks). Arg54 makes a hydrogen bond with LPPG, which is bound in a continuous cavity. Residues Leu7, Tyr38, Tyr44, and Tyr47 in the

\section{Wheat LTP2}

The solution structure of wheat TaLTP2.1 in complex with LPPG (PDB ID 1N89; Pons et al. 2003) (Table 3) revealed a structure consisting of five helices arranged in a superhelical tertiary structure. The cavity volume $\left(341 \AA^{3}\right)$ of TaLTP2.1 is in the same range as TaLTP1.1, although TaLTP2.1 is shorter by 24 residues (Pons et al. 2003). Only one unique phospholipid position was found for LPPG in all retained solution structures of TaLTP2.1 (Fig. 7a). The fatty acid chain is completely embedded in the protein, and the terminal methyl group of the fatty acid chain is positioned between the $\mathrm{H} 1$ and $\mathrm{H} 4$ helices. The proximal entrance of the cavity, where the phosphate group of the lipid is found, is characterized by several hydrophilic and basic residues; Arg49, Arg54, Thr58, and His66. The distal opening of the cavity presents hydrophobic residues, such as Leu7, Tyr38, Tyr44, and Tyr47.

The crystal structure of the TaLTP2.1 in complex with LPPG showed two independent ligand binding sites (Fig. 7b; PDB ID 1TUK; Hoh et al. 2005). The major lipidbinding site is the large and long cavity, with the shape of an elongated curved channel of about $17 \AA$ length and $5 \AA$ in diameter with a volume of $300 \AA^{3}$, and the minor cavity has a volume of $130 \AA^{3}$. In the X-ray structure, the residues Leu7, Ile14, and Leu28 form the bottom of the main cavity and define the wall to the minor cavity (Hoh et al. 2005), whereas in the solution structure, they have a different

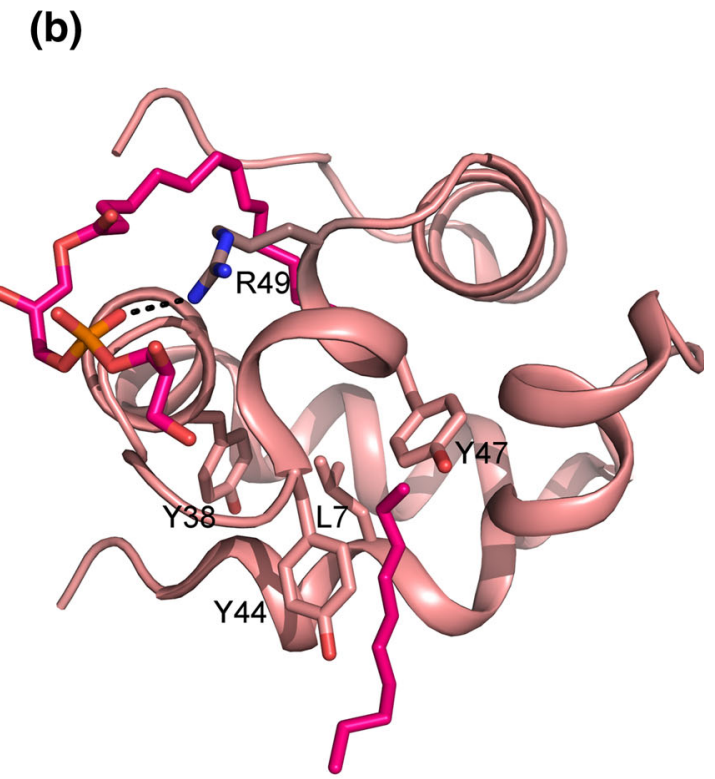

distal opening are shown as sticks. b The X-ray structure of TaLTP2.1 (pink) in complex with two LPPG molecules (magenta). One of the LPPG molecules forms a hydrogen bond with Arg49 instead of Arg54 
orientation that allows the formation of one continuous cavity (Pons et al. 2003).

\section{Arabidopsis DIR1}

The Arabidopsis AtLTPd1 (DEFECTIVE IN INDUCED RESISTANCE; DIR1) was crystallized in complex with two molecules of LSPC (Table 3). DIR1 follows the general LTP-fold, with five helices connected by four disulfide bonds arranged in a super-helical pattern around a central tunnel-shaped cavity (Fig. 8; PDB ID 2RKN; Lascombe et al. 2008). After an elongated N-terminal segment followed by a turn, the DIR1 structure begins with a long $\alpha$ helix (H1). Three residues in 3/10-helix conformation complete this first $\alpha$-helix. In wheat TaLTP2.1, the 3/10 helix forms an angle of $\sim 90^{\circ}$ with the H1, while in DIR1, $\mathrm{H} 1$ and the second $3 / 10$ helix are almost collinear. This opens up the central channel of DIR1, allowing entry and room for two lipid molecules. The volume of the cavity is $242 \AA$ after removing the two lipids. The cavity is fully lined with hydrophobic residues, while some polar residues are located around the large tunnel entrance. The C-terminal segment has no defined secondary structure, except for the last residue, Cys77, which is involved in a disulfide bond.

In DIR1, the four cysteine pairs are Cys5-Cys42, Cys15-Cys31, Cys32-Cys69, and Cys44-Cys77 accordingly to what is found for the LTP2-family. Moreover, the size of DIR1 is also closer to LTP2 than to LTP1. Similar to the solution structure of wheat TaLTP2.1 (Fig. 7a; Pons

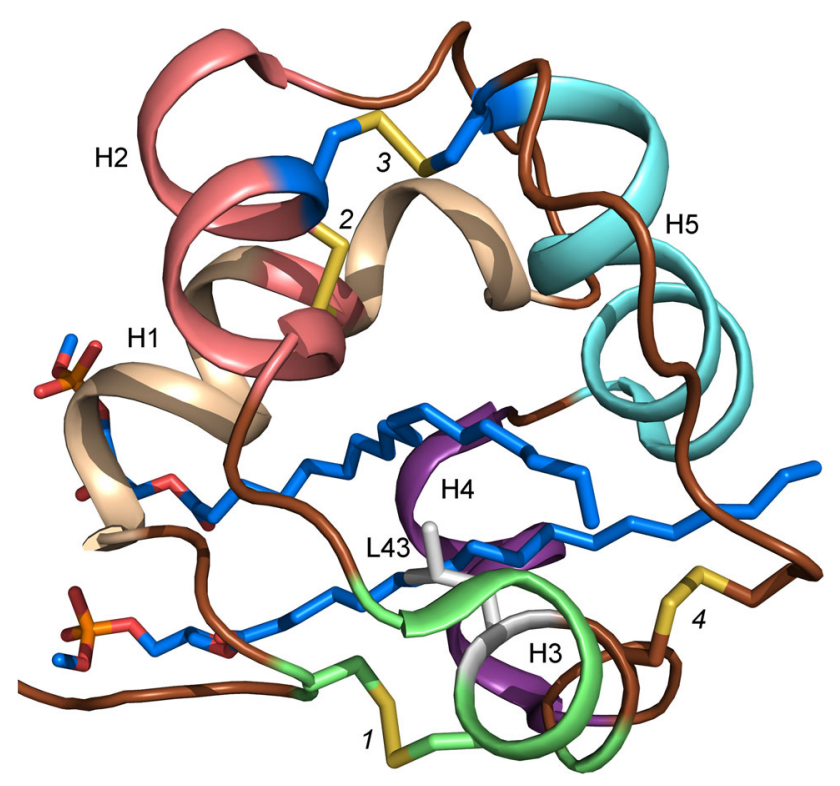

Fig. 8 The X-ray structure of DIR1. The disulfide bonds are formed similarly as in LTP2s. The residue in the $\mathrm{C}^{5} \mathrm{XC}^{6}$ motif is the buried and hydrophobic Leu43. The lipid binding site accommodates two LSPC (blue sticks) in the binding site et al. 2003), in DIR1, the two bound LSPC molecules are fully extended, arranged side by side, parallel to each other in the same cavity (Fig. 8). On the other hand, in the X-ray structure of wheat TaLTP2.1, the two ligands are located in two different compartments (Fig. 7b; Hoh et al. 2005).

When the lipid binding of DIR1 was tested with LPC derivatives carrying acyl chains of different lengths, it was more efficiently binding longer fatty acyl chains (C18) than shorter chains (C14) (Lascombe et al. 2008). The $K_{\mathrm{d}}$ for binding to LMPC was $0.3 \mu \mathrm{M}$, for LPPC $0.03 \mu \mathrm{M}$, and for LSPC $0.06 \mu \mathrm{M}$. These data may be compared to wheat TaLTP1.1 for which the $K_{\mathrm{d}}$ values for binding to the LMPC, LPPC, and LSPC are 0.4, 0.7, and $0.7 \mu \mathrm{M}$, respectively (Douliez et al. 2000).

\section{Physcomitrella LTP}

The structure has not been determined experimentally for any LTPs from early diverging land plants, such as mosses or livermosses. Molecular modeling suggests that LTPds and LTPgs from the livermoss Marchantia polymorpha and the moss $P$. patens have similar $8 \mathrm{CM}$ and disulfide bond patterns as LTPd and LTP2 (Edstam et al. 2011). When the lipid binding of two LTPgs from $P$. patens was tested in a TNS competition assay with saturated and cis-unsaturated C18 fatty acids, both PpLTPg2 and PpLTPg8 showed a preference for cis-unsaturated fatty acids (Edstam et al. 2014). The competition assay further revealed that the moss LTPGs were more readily binding to stearoyl-CoA compared to stearate. The $\omega$-hydroxy fatty acid 22-hydroxydocosanoic acid was found to compete with less efficiency for binding to the PpLTPgs than oleic acid, linoleic acid, and stearoyl CoA. The $\omega$-hydroxy fatty acids are major components of plant surface polyesters, such as suberin and cutin, and could, therefore, possibly be a natural ligand for the LTPs.

\section{Functional investigations of LTPs}

There are numerous reports demonstrating the expression pattern of individual LTPs (Boutrot et al. 2007; Li et al. 2014a; Wei and Zhong 2014; Yu et al. 2014). One conclusion that can be drawn from these experiments is that LTPs are abundantly expressed in all tissues of the plant. To take the expression analysis further, microarray data were exploited and analyzed for coexpression patterns of LTPg genes in rice and Arabidopsis. The results showed that based on coexpression LTPgs can be arranged in three clusters (AtI-III and OsI-III). Each expression cluster contains 3-8 LTPg genes. In one cluster from each plant, AtI in Arabidopsis and OsI in rice, the expression is restricted to aerial parts of the plant. The second cluster, 
AtII or OsII, is the only one with expression in roots, while expression of the third cluster, AtIII or OsIII, is restricted to reproductive tissues. Gene ontology analyses of the Arabidopsis clusters indicate that the AtI is primarily involved with cuticular wax accumulation, AtII with suberin synthesis or deposition and AtIII with sporopollenin accumulation (Edstam et al. 2013). Thus, there are defined clusters of LTPs with common expression patterns, at least in both Arabidopsis and rice. Each LTP cluster likely operates to complete a specific biological process.

\section{LTPs play a role in signaling}

It has been rather challenging to connect LTP knock-downs or knock-outs with phenotypes, probably due to a high degree of gene redundancy. However, since the first phenotype for an LTP mutant was reported for about 15 years ago, there has been a slow but steady accumulation of LTPrelated phenotypes. The wide array of phenotypes reported reveals that the LTPs play important roles in many different tissues and organs of plants.

The Arabidopsis AtLTPd1 (DIR1) was the first LTP where a mutation could be connected to a phenotype. The analysis of the dirl-1 mutant revealed a role in systemic resistance signaling for DIR1 (Maldonado et al. 2002). The dirl-1 plants exhibit WT local resistance towards infection with Pseudomonas syringae. However, the pathogenesisrelated gene expression pattern is abolished in uninoculated distant leaves. Thus, the inoculated leaves in the dirl-1 plants are defective in the production or transmission of a mobile signal.

A related phenotype is found for Arabidopsis AZELAIC ACID INDUCED 1 (azil) plants. AZL1 (At4g12470) is encoding an LTP-like protein. It has an $8 \mathrm{CM}$, but unlike the classical LTPs, there is a proline-rich region inserted between the targeting sequence and the $8 \mathrm{CM}$. Azelaic acid and petiole exudates failed to induce systemic immunity in azil plants, although these treatments protected WT plants against subsequent infection (Jung et al. 2009). In addition, pathogen-induced exudates from azil were inactive when applied to WT plants.

Thus, like DIR1, AZI1 modulates production and/or translocation of a mobile signal during systemic acquired resistance (SAR). The phosphorylated sugar derivative glycerol-3-phosphate (G3P) is one of many chemical signals that contribute to SAR. In recent studies, it has been shown that DIR1 and AZI1 are essential for G3P-accumulation, while on the other hand, reduced levels of G3P result in decreased DIRI and AZII transcription (Yu et al. 2013). It seems that G3P operates in a positive feedback loop with DIR1 and AZI1. The mechanistic details of the feedback loop remain unknown.

\section{LTPs are required for cuticular wax accumulation}

AtLTPg1 (LTPG1) and AtLTPg2 (LTPG2) from Arabidopsis are both highly expressed in the epidermis of inflorescence stems and silique walls (Debono et al. 2009; Kim et al. 2012). Knock-down of LTPG1 expression results in reduced wax load on stem surfaces (Debono et al. 2009), while a ltpgl T-DNA knockout mutant shows a $10 \%$ reduction of the C29 alkane (nonacosane) in stems and siliques (Lee et al. 2009). The C29 alkane is the major component of cuticular wax in stems and siliques. In a ltpg2 knock-out mutant, the amount of the $\mathrm{C} 29$ alkane is reduced with $4 \%$ in stems and $20 \%$ in siliques (Kim et al. 2012), whereas a ltpgl ltpg2 double-mutant shows even further reductions of the C29 alkane. Kim and coworkers (2012) could also demonstrate a reduced total wax load in the stems and siliques of the ltpg1 ltpg2 double-mutant and in the siliques of the ltpg 2 single mutant. No alterations of the total wax load were found for ltpgl in this study by Kim et al. (2012).

Overexpression of the Brassica rapa BrLTPd1 in Brassica napus causes a reduced wax deposition on leaves. When the chemical composition of leaves from a line overexpressing the BrLTPd1 was determined, it was found that the C31 alkane (hentriacontane) was reduced with $78 \%$ and the C29 alkane was reduced with $44 \%$. Overexpression of BrLTPd1 also induces morphological changes of leaves and flowers in B. napus (Liu et al. 2014). There are also several LTPs from monocot plants that have expression patterns suggesting a role in wax or cutin deposition. For instance, the barley HvLTP1.2 (LTP7a2b) has a strong expression in epidermal leaf strips (Hollenbach et al. 1997). The precise role for the LTPs in the cuticular wax synthesis is not clear. The LTPs may act directly in the transport of cuticular lipid through the cell wall or alternatively as a regulatory component for the transport.

\section{LTPs are functioning in liquid secretion}

The tobacco NtLTP1.2 is present in the liquid droplets that are secreted by cells of the long glandular trichomes on the leaves (Choi et al. 2012). In transgenic tobacco that overexpresses NtLTP1.2, there is an increased liquid secretion from the trichomes compared to WT. In plants where NtLTP1.2 expression has been silenced with RNAi, the liquid secretion is decreased. The compounds secreted from the long glandular trichomes confer resistance to insect pests. Consequently, Choi et al. (2012) could show that NtLTP1.2 overexpressing lines have an increased resistance to aphid infestation. The opposite was found for the NtLTP1.2 RNAi silencing lines, which showed increased aphid infestations. Expression in epidermal cells 
including trichomes was also found for wheat TaLTP1.3. Its promoter is active in young leaves, shoots and spikes but not in roots (Yu et al. 2014). However, no phenotype is yet connected to this wheat LTP.

\section{LTPs are needed for pollen and seed development}

The LILTP1.1 (SCA) from Lilium longiflorum (lily) was the first LTP suggested to have a role in the sexual reproduction of plants (Park et al. 2000). SCA is involved in pollen tube adhesion-mediated guidance during pollen tube growth. It seems that SCA forms an adhesive matrix with pectin that guides the pollen tubes to the ovules (Park et al. 2000). On the basis of sequence similarity, seven SCA-like LTPs were identified in Arabidopsis (Chae et al. 2010). When T-DNA insertion mutants for those seven genes were investigated, only AtLTP1.8 (LTP5) showed a phenotype.

In the ltp5-1 mutant an aberrant, unspliced transcript is accumulating due to the localization of the T-DNA close to $3^{\prime}$ splice recognition site of the only intron in the gene. In the presence of the aberrant ltp5-1 transcript, plants have defects in pollination and seed formation, such as that the majority of the ltp5-1 pollen tubes reach only the middle of the ovary and the ltp5-1 silliques contain significant numbers of unfertilized ovules (Chae et al. 2009). Another T-DNA insertion allele without detectable LTP5 expression does not show any mutant phenotype. Thus, the presence of an aberrant LTP5 in the ltp5-1 mutant seems to contribute to the phenotype as a gain-of-function mutation. Based on the ltp5-1 phenotype, LTP5 is suggested to be involved in establishing or maintaining polar growth of the pollen tube. As revealed from LTP5 promoter:GUS fusion lines, LTP5 has a unusually wide expression pattern with expression in root tips, at initiation sites for lateral roots, hypocotyls, shoot apex, cotyledons, first leaves, pollen, style, and petals (Chae et al. 2010).

After the discovery of SCA1, several other LTPs with a function in pollen development and fertilization have been identified. CaLTPc1 from Capsicum annuиm L. (chili pepper) was identified as a differentially expressed gene in male fertile lines of chili pepper (Chen et al. 2011). It is strictly expressed during the middle phases of anther development. When virus-induced gene silencing was used to shut down expression, the silenced plants showed normal vegetative growth and flowering. However, the pollen from CaLTPc1-silenced plants had lower germination efficiency and significant shorter pollen tubes. Moreover, a large number of the pollen grains have a defective morphology with deep invaginations.

The rice OsLTPg25 (OsC6) is expressed in tapetal cells and microspores during the post-meiotic stages 9-11 of anther development, according to the developmental stages of the rice flower defined by Zhang and Wilson (2009). In immunological assays, the OsC6 protein was detected in tapetal cell cytoplasm, the extracellular space between the tapetum and the middle layer, as well as in the anther locule and anther cuticle (Zhang et al. 2010). Silencing of OsC6 with RNAi result in reduced pollen fertility. In OsC6 silenced plants, the anthers follow normal development until stage 8 . At late stage 9, the development is clearly different in the silenced plants, such as that free young microspores are released from the tetrad. Furthermore, tapetal cells are degenerated and microspores have irregular shapes and became shrunken. At later stages of anther development, the OsC6-RNAi lines develop fewer normal orbicules and irregular pollen walls. Ectopic expression of OsC6 results in granule-like droplets on the inner surface of the tapetal cells. The phenotypes obtained in knockdowns and overexpressors are suggesting a key role for OsC6 in transporting lipophilic material required for proper pollen development from the tapetal cytoplasm to the locule (Zhang et al. 2010).

The Arabidopsis AtLTPc1, AtLTPc2, and AtLTPc3 all have an expression pattern restricted to the tapetum of developing anthers (Huang et al. 2013). When the promoter and coding region of AtLTPc3 was fused to GFP, it was found that during stages 7-9 of floral development (Smyth et al. 1990) AtLTPc3 is localized to the anther locule, while starting from stage 9, it is also associated with the microspore surface. Double RNAi silencing of AtLTPc1 and AtLTPc3 did not reveal any abnormalities on the pollen surface, and the pollen showed no reduction in fertility. However, the intine underneath the exine is somewhat impaired in the stage 11 microspores of RNAi plants, as it appears separated from the exine and the microspore plasma membrane (Huang et al. 2013).

The Arabidopsis LTPgs AtLTPg2, AtLTPg3, AtLTPg4, AtLTPg5, and AtLTPg6 are all involved in the development of pollen and seed. The Atltpg3-1, Atltpg4-1, and Atltpg4-2 T-DNA single mutants have deformed or collapsed pollen grains (Edstam and Edqvist 2014). Furthermore, seeds from the single mutants Atltpg2-2, Atltpg3-1, Atltpg4-1, Atltpg4-2, Atltpg5-1, Atltpg6-1, and Atltpg6-2 have an inability to restrict salt uptake. In the case of Atltpg4-1, Atltpg4-2, and Atltpg5-1, the seeds had abnormal phenotypes, such as the protrusion of seed hairs, or a shrunken and deformed appearance. Lipid analysis of the seed coats from Atltpg4-1, Atltpg4-2, Atltpg6-1 and Atltpg6-2 revealed a large decrease in $\omega$-hydroxy fatty acids and an increase in unsubstituted fatty acids. Among the unsubstituted fatty acids, the largest difference between the mutant lines and the WT was the increase in C20:0, C22:0, and C24:0 fatty acids in the mutant lines. For the $\omega$ hydroxy fatty acids, the largest decrease is seen for 24-hydroxytetracosanoic acid $(\mathrm{C} 24 \omega \mathrm{OH})$, which is an 
important constituent of suberin. Suberin is one of the main barrier polymers (Vishwanath et al. 2015). It is synthesized to create a hydrophobic barrier against uncontrolled water and solute diffusion through cell walls. Suberin is found in seed coats, but also in perodermal and endodermal cell walls in roots. Seemingly, these Arabidopsis LTPgs are involved in the transport of polyester components to the site of polyester synthesis on the surfaces of pollens and/or seeds.

There are also several examples of LTPs that have an abundant expression in floral organs, fruits or seeds but where a phenotype not yet has been reported. The promoter of rice OsLTPd11 (OsLTP6, OsDIL) is specifically active in anthers from the microspore mother cell developmental stage (stage 6 as defined by Zhang and Wilson 2009) to the mature pollen stage (stage 14) (Guo et al. 2013a; Liu et al. 2013). A pistil-specific LTP, SsLTP1.1, is expressed in the Asteraceae Senecio squalidus (Allen et al. 2010). In $N$. tabacum, a pistil-preferential LTP (TOBC065A09) was identified in microarray experiments (Quiapim et al. 2009). A stigma specific LTP (contig C1000870:1) from Crocus sativa L. (saffron) was identified during sequencing of ESTs from a saffron stigma cDNA library (D'Agostino et al. 2007). Microarray analysis and sequencing of a stigma-enriched cDNA library from Arabidopsis revealed that both AtLTP1.5 and AtLTPg21 have enhanced expression levels in the stigma (Swanson et al. 2005). The mung bean VrLTP1.2 (Vrltp1) and VrLTP1.3 (Vrltp2) are both expressed in floral buds and in the embryo during early embryogenesis, but not in mature or dehydrated seeds (Liu and Lin 2003).

\section{LTPs are important for fruit development and seed germination}

Gene expression patterns indicate that LTPs also play important roles during fruit development and seed germination. In Coffea arabica, CaLTP2.1, CaLTP2.2, CaLTP2.3, and CaLTP2.4 are expressed in the pericarp and endosperm during fruit development with peaks 90-120 days after flowering (Cotta et al. 2014). The expression of maize ZmLTPd6 (BETL9) is restricted to developing kernels. The transcript could be detected 11 days after pollination and only in RNA extracted from the lower halves of the kernels, thus in the basal endosperm transfer cell (ETC) layer. The closely related ZmLTPd14 (BETL9like) is also specifically expressed in developing maize endosperm within the same time frame as BETL9, but rather in the aleurone cell layer (Royo et al. 2014).

GUS analysis of the promoters of wheat TaLTPd1 (TaPR60) and Triticum durum TdLTPd1 (TdPR60) showed that the promoter activity of both genes is restricted to the ETC. The homologous T. durum protein TdLTPd2 (TdPR61) has a wider expression pattern in the endosperm, since the promoter is active in the ETC, the aleurone, and the starchy endosperm (Kovalchuk et al. 2009, 2012). In Euphorbia lagascae, ElLTP1.1 and ElLTP1.2 are expressed specifically and abundantly in the endosperm during seed germination (Edqvist and Farbos 2002; Eklund and Edqvist 2003).

The expression patterns of Arabidopsis AtLTPd9 (END1) and AtLTPd12 (END2) indicate roles in reproduction also for these proteins (Li et al. 2014b). The AtLTPd9 transcripts are abundant in flowers before pollination and increase even more in young green siliques. Furthermore, when the activity of an AtLTPd9 promoter:GUS fusion was followed in Arabidopsis, particularly strong GUS expression was detected in dividing nuclei, endosperm nodules and in the developing embryo at the globular stage of embryo development. AtLTPd12 transcripts are mainly accumulating in flowers before pollination, and the transcript levels are reduced in the siliques. VuLTP1.1 (VULTP) from Vigna unguiculata (cowpea) is another LTP which is accumulating during seed development. VuLTP1.1 is also expressed in seedling leaves, but not in roots, leaves, and flowers of adult plants (Carvalho et al. 2006).

\section{LTPs are involved in cell expansion}

The tobacco NtLTP1.6 (TobLTP2) was demonstrated to have in vitro cell-wall loosening activity (Nieuwland et al. 2005). This is an activity usually attributed to expansins. Pre-incubation of NtLTP1.6 with $\beta$-sitosterol or benzene completely abolished the cell-wall loosening activity suggesting that the availability of the hydrophobic cavity is essential for the cell-wall loosening.

\section{LTPs are important for nodule formation}

Medicago truncatula, like other legumes, forms $\mathrm{N}^{2}$ fixing root nodules after symbiotic interactions with microorganisms. The $M$. sativa MsLTPd1 (MtN5) has a root specific expression pattern, and it is upregulated in response to symbionts, such as Sinorhizobium meliloti or pathogenic microorganisms, such as Fusarium semitectum. The protein is produced during the early stages of the symbiotic interaction and is localized to mature root nodules (Pii et al. 2012). Ligand-binding studies in vitro showed that MsLTPd1 binds to LLPC and LPPC (Pii et al. 2009). In $M$. truncatula roots where MsLTPd1 expression is silenced with RNAi, there is an increase in root hair curling after rhizobia infection. Furthermore, there is a decrease in the number of invaded roots compared to WT. Nonetheless, the total number of nodule primordia is not varying between WT and MsLTPd1-silenced plants (Pii et al. 2012). From these experiments, Pii et al. (2012) raised the hypothesis 
that MsLTPd1 is involved in modulating the perception or the activity of rhizobia-derived signal molecules.

Another LTP involved in nodule organogenesis is AsLTP1.1 (AsE246) from Astragalus sinicus (Chinese milk vetch) (Lei et al. 2014). Chinese milk vetch can establish a specific endosymbiosis with Mesorhizobium huakuii $7653 \mathrm{R}$ and form $\mathrm{N}_{2}$-fixing root nodules. In lipid binding assays, based on competition with P-96 for binding to AsE246, fatty acids with 16- to 18-carbon chains showed higher competition, while shorter (laurate and myristate) and longer (arachidic acid and behenic acid) fatty acids were competing with less efficiency. Furthermore, also the membrane lipids PC, phosphatidylethanolamine (PE), phosphatidylinositol (PI), digalactosyldiacylglycerol (DGDG), and monogalactosyldiacylglycerol (MGDG) could compete with P-96 for binding to AsLTP1.1. AsLTP1.1 is localized to nodule cells containing symbiosomes. Ectopic overexpression of AsLTP1.1 results in increased numbers of root nodules. When AsLTP1.1 expression is knocked down with RNAi, there is a significant decrease in formed root nodules. The nodules from the RNAi plants also contained fewer infected cells (Lei et al. 2014). It is possible that the function of AsLTP1.1 is related to the transport of plant-synthesized lipids to the symbiosome membrane.

\section{LTPs could be involved in root suberin synthesis}

Other than being important for nodulation, there are likely other functions for LTPs in roots. It has been suggested that LTPs are involved in the synthesis and accumulation of suberin in roots, as also shown for the suberin synthesis in seed coats. The support for a role of LTPs in suberin accumulation in roots is so far based on analysis of expression and co-expression. As described earlier, the LTPgs from Arabidopsis and rice are separated in three expression cluster, of which one of the clusters showed significant co-expression with genes known to be involved in suberin biosynthesis in roots (Edstam et al. 2013). In Arabidopsis, AtLTPg3, AtLTPg4, AtLTPg23, and AtLTPg26 belong to the expression cluster correlating with suberin biosynthesis, while in rice, OsLTPg1, OsLTPg2, and OsLTPg24 were pointed out to have putative roles in suberin biosynthesis. Possibly, the root LTPs could be involved in the trafficking of suberin precursors to polymerization sites in the cell wall. Further experimental studies will be required to determine the precise role of LTPs in suberin synthesis in roots and elsewhere.

\section{LTPs are involved in defense against biotic stress}

There are several studies that suggest that LTPs are toxic for fungal plant pathogens. Several wheat LTPs
(TaLTP1.4, TaLTP1.13, TaLTP1.17, TaLTP1.18, TaLTP1.25-1.28) were expressed in P. pastoris and then analyzed in in vitro growth inhibition tests (Sun et al. 2008). Most of the tested LTPs showed inhibitory effect for the growth of the wheat pathogens Puccinia graminis, Puccinia triticina, and Pyrenophora tritic-repenti. The in vitro toxicity of the LTPs could be derived from an alteration of the fungal membrane permeability, as the fungal uptake of the fluorescent probe SYTOX green increased in the presence of the inhibitory wheat LTPs.

The wheat TaLTP1.14 is associated with resistance against Fusarium head blight, caused by Fusarium graminearum as this LTP is 50 -fold more abundant in wheat plants carrying the resistant allele Qfhs.ifa-5A (Schweiger et al. 2013). On the other hand, the wheat TaLTP1.23 (Hfr-LTP) shows a 196-fold decrease in abundance in susceptible plants over the first eight days of attack by the virulent Hessian fly larvae. A similar pattern, although with a less dramatic decrease, was also found for TaLTP1.16 (TaLTP3) (Saltzmann et al. 2010). The transcription of Hfr-LTP did not respond to other tested biotic and abiotic stresses. Moreover, the expression of cowpea VuLTP1.1 in seedling leaves is repressed to $60 \%$ after infection with the fungi Fusarium oxysporum f. sp. phaseolus (Carvalho et al. 2006).

\section{LTPs are involved in defense against abiotic stress}

The LTPs are often reported to be important for tolerance to abiotic and biotic stresses in plants. Still, there are, to our knowledge, no examples of a plant where either knock-out, knock-down or overexpression of an LTP result in a phenotype showing increased sensitivity or increased tolerance to stress. Anyway, there are many cases where the expression of LTP-genes is responding to abiotic stresses like drought, cold, and salt or to phytohormones, such as abscisic acid (ABA). Here, we will only give some examples from recently published reports. For instance, the transcript levels of Arabidopsis AtLTP1.12 are dramatically induced by dehydration and ABA treatment (Guo et al. 2013b). LjLTP1.1 (LjLTP6) and LjLTP1.3 (LjLTP10) from Lotus japonica are specifically expressed in aerial tissues. Both genes are highly induced during drought (Tapia et al. 2013). The expression of rice OsLTPd11 is also greatly induced by drought and also by $\mathrm{PEG}, \mathrm{NaCl}$, cold, and $\mathrm{ABA}$ (Guo et al. 2013a). The wheat LTPs TaLTP1.2 and TaLTP1.13 are upregulated during drought, chilling stress, and wounding ( $\mathrm{Yu}$ et al. 2014). In maize, 14 LTPs are differentially regulated by drought, salt and/or re-watering treatments, while three other maize LTPs are upregulated during cold stress (Wei and Zhong 2014).

When the expression of eight LTPgs in the moss $P$. patens was investigated during different stress treatments, 
cold and dehydration caused a significant upregulation of several of the genes. For instance, PpLTPg3, PpLTPg8, and PpLTPg9 are significantly upregulated after cold treatment, while PpLTPg5 is downregulated. Dehydration causes a significant upregulation of PpLTPg2, PpLTPg3, PpLTPg6, and PpLTPg9. Thus, PpLTPG3 and PpLTPG9 are upregulated after both cold treatment and dehydration. Treatment of the moss with UV-B radiation, $\mathrm{ABA}$, and salt leads to downregulations of the PpLTPg genes (Edstam et al. 2014).

\section{Summary and outlook}

Plants conquered land at least 500 million years ago. Since those days the LTPs have carried out necessary, life-supporting functions in all land plants, in all tissues and during all stages of the life cycle. In this review, we have summarized the current information about the 3D structure, ligand binding, gene expression, and phenotypic investigations regarding the LTPs. The first 3D structures of LTPs were presented in the early 1990s, and a quite large number of papers describing the structural or ligand binding properties of LTPs have been published since then. The hydrophobic ligand-binding cavity is flexible and often swells when a lipid ligand is binding. Several LTPs fit two fatty acyl chains in their binding cavities. Upon binding a ligand, the structural alterations are quite limited and significant structural rearrangements occur mainly in the C-terminal part of the LTPs. In other parts of the protein, there may be more local rearrangements of 1-2 amino acids. A Tyr residue close to the opening of the cavity, Tyr79 in TaLTP1.1, is a key residue in many LTPs. Seemingly, the orientation of this Tyr residue often controls the shape, size, and binding capacity of the hydrophobic cavity. In unliganded LTP structures, Tyr79 often collapsed into the ligand binding cavity. Many ligands cause a shift in the orientation that move the aromatic ring of Tyr79 outwards to the solvent. This orientation excludes the formation of hydrogen bonds between Tyr79 and the ligand. Tyr79 may act as a gate keeper of the cavity and the rotation ensures that high specificity interactions with ligands are avoided. However, Tyr79 in TaLTP1.1 has an important role in the binding of $\mathrm{PGB}_{2}$ as in that case rotation of Tyr79 enables a hydrogen bond between the carboxyl group of the ligand and the hydroxyl group of Tyr79. It is clear that the properties of the ligand influence the 3D structure of the LTP.

Several in vitro binding experiments show that LTPs bind both saturated and unsaturated fatty acyl chains, presented in various molecules, such as in LPC, PG, acylCoA or as free fatty acids. Some LTPs are reported to bind to hydroxylated acyl chains, while only rice LTP2 is reported to bind to a sterol. The dissociation constants $\left(K_{\mathrm{d}}\right)$ for LTP-ligand interactions are commonly in the micromolar range indicating that the LTPs are involved in lowaffinity interactions. The preferred ligands are, in most cases, fatty acyl chains with 14-18 carbons. Unfortunately, the ligand-binding studies have rarely improved our functional understanding of the LTPs. We are still rather clueless about their in vivo binding repertoire. However, we probably have to accept that any lipid or other hydrophobic molecule, within a certain molecular size range, will fit into the cavity of these promiscuous proteins.

LTPs are expressed in all tissues and at every developmental stage of the plant. Nevertheless, each unique LTP is likely acting in a very specific set of tissues during specific stages of the life cycle. Based on the gene expression patterns, the LTPs in seed plants can be functionally classified into root LTPs, green LTPs, and reproductive LTPs, expressed in roots, green tissues, and floral tissues, respectively. This functional classification fits well with the experimental evidence showing that the LTPs are involved in the synthesis of cuticular waxes on leaves, in suberin synthesis in seed coat and roots, in sporopollenin synthesis of the exine walls of pollen grains, in adhesive polymer synthesis in the style (Park et al. 2000). Clearly, the major role of many LTPs is in the accumulation of the complex barrier polymers on the surfaces of tissues and organs in plants. These lipid-based polyesters form barriers that control the fluxes of gases, water, and solutes, and also play roles in protecting plants from biotic and abiotic stresses and in controlling plant morphology and reproduction. The evolution of the biosynthesis of these polymers was absolutely essential for the successful colonization of land by plants for approximately 500 million years ago (Wellman et al. 2003).

The cuticle, suberin, and sporopollenin polymers all have an extremely complex and heterogeneous nature, and the details of their synthesis are still elusive. The lipid polymer synthesis requires the de novo synthesis of polymer precursors, the massive secretion and export from the lipid bilayer. Once exported from the plasma membrane, the extremely hydrophobic polymer compounds have to pass through an outer compartment, such as the apoplast or the locule, to the actual polymerization sites. The data we have reviewed here suggest that many LTPs are important for this cell exterior transport of precursors for the synthesis of lipid-based polymers.

It is still rather unclear how the LTPs are running the exterior transport of building blocks for lipid polymer synthesis. There are some low-resolution models, which attempt to explain the rational and mechanisms behind the role of LTPs in polymer synthesis. In these models, ABC transporters are moving lipid polymer components through the plasma membrane. On the exterior side of the plasma 
membrane, the lipids are transferred to LTPs. The LTPs continue the transport and shuttle the lipid polymer components from the plasma membrane to the sites of polymer synthesis, which, for instance, could be the surfaces of stems or pollen (Fig. 9). Possibly, the ABC transporters deliver the polymer building blocks to LTPgs, which are attached to the membrane through their GPI-anchor. The cargo is then transferred from LTPg to other LTPs that may diffuse freely in the space outside the plasma membrane (Fig. 9). The challenge now is to design experiments that could approve or disapprove this model for LTP function. For this purpose, it will, for instance, be useful to obtain conclusive results regarding the in vivo localization and the in vivo molecular interactions of individual LTPs. One way forward could be to use sophisticated visualization tools, such as super-resolution microscopy, to follow the movement of specific LTPs in the plant.

Based on our current knowledge, the major LTP types are not functionally specialized. Rather, LTPs from one single type are often involved in many different processes in several parts of the plants. LTP1 are involved in cell expansion, lipid secretion, nodule development, and pollen tube growth. LTPd is important for systemic resistance signaling, cuticular wax accumulation and are also involved in nodule development. The GPI-anchored LTPg are also active in a number of different processes, such as cuticular wax accumulation, pollen exine formation, and seed coat suberin polymerization. LTPc seems to be more functionally specialized. The LTPc genes are strictly expressed in developing anthers where the LTPc proteins probably are involved in the transport of lipid required for the biosynthesis of the pollen exine.

One would expect that there are identifiable features in sequence or structure separating LTPs involved in the synthesis of one lipid polymer from the LTPs involved in synthesis of another polymer. Thus, sequential or structural motifs would reveal whether the LTP is involved in, for instance, cutin biosynthesis in stems and leaves or required for the suberin biosynthesis in seed coats. There could, for example, be similarities in the ligand binding cavity or on the protein surface. So far, such distinguishable features have not been identified. However, one should note that both the functional and structural investigations are in a rather early stage. Most of the structural studies have been done on LTPs from seeds, and there are just a few protein structures from LTPs expressed in other tissues. Furthermore, the mechanistic details of how the LTPs act are still lacking. The accumulation of more data may reveal that LTPs involved in the same or similar process share structural characteristics important for their specific functional purpose.

Interestingly, there are some LTPs, which are involved in other processes than lipid polymer biosynthesis. One
Fig. 9 A schematic model describing the proposed functions for LTPs in green tissues (a), in roots (b), and in pollen (c) (a) Tranport to cuticle in epidermal cell of aerial tissue

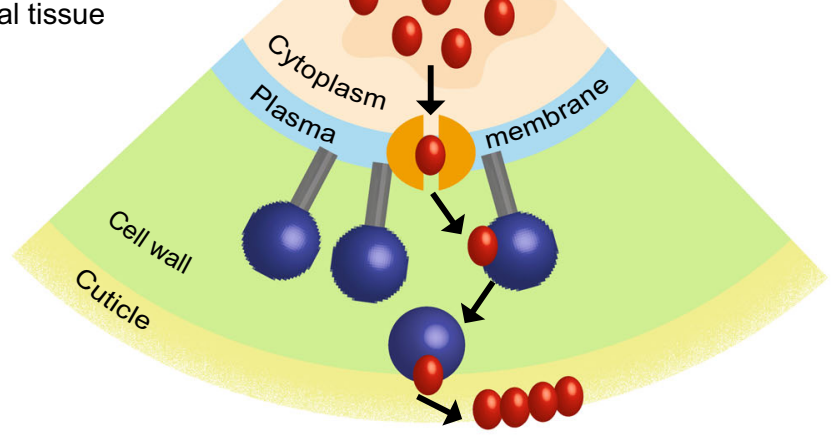

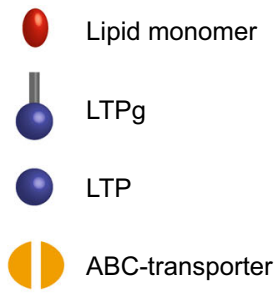

ABC-transporter (b) Tranport in epidermal cell of root

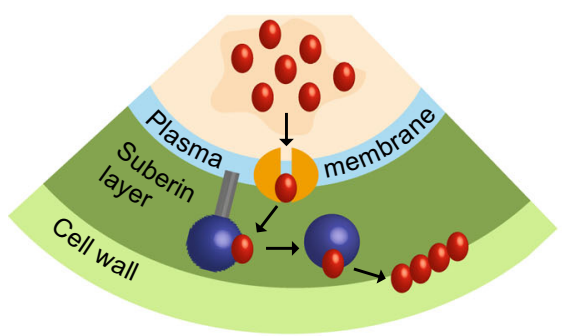

(c) Transport in pollen

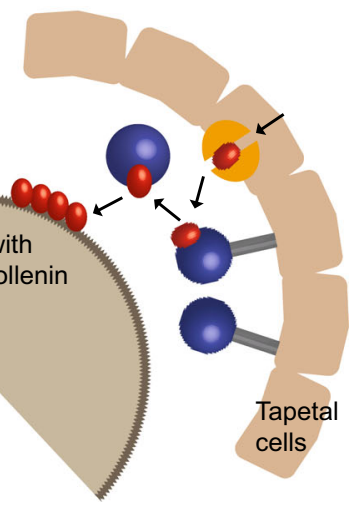


example is AtLTPd1 (DIR1), which is involved in SAR following the exposure to a pathogen. During SAR, DIR1 is moving from the induced leaf down the petiole to distant leaf petioles (Champigny et al. 2013). The highly similar protein AtLTPd2 (DIR1-like) may also contribute to SAR, as the dirl-1 mutant displays a partially SAR-competent phenotype (Champigny et al. 2013). G3P is one of several chemical inducers of SAR (Gao et al. 2014). DIR1 and also the LTP-like AZI1 are reported to be required for pathogen-induced biosynthesis of G3P in Arabidopsis (Yu et al. 2013). The detailed mechanisms how DIR1 activates SAR have not been revealed yet. At present, there is no experimental evidence suggesting similar roles for other LTPs. Anyway, it would be rather peculiar if only one or two proteins of the large LTP family would be involved in signaling, it is tempting to speculate that we will soon learn about other LTPs with its main function in signal transduction.

The research on LTP has now formed a solid ground, and it is a good time to advance forward with more exciting experiments on these intriguing and fascinating plant proteins. There are many challenges involved in LTP research, such as the intricate gene families resulting in gene redundancy, the low specificity of the ligand:LTP interactions and the complex nature of the lipid polymer synthesis. Anyway, with systematic approaches, it will definitely be possible to significantly advance our knowledge in a few years from now. The reward may be a much improved knowledge about the details of LTPs, but also more importantly an advanced general understanding about plant evolution and physiology as well as about protein function and structure. One way forward could be to use sophisticated microscopy to trace the movements of LTPs in living cells. However, it is also of importance to continue with more basic experiments such as knock-down or overexpression strategies followed with detailed phenotypic investigations. So far, crystal and solution 3D protein structures have mainly been obtained from seed LTPs. Therefore, it is very important to get protein structure information for other LTPs expressed in other tissues and organs. There could also be more emphasis on finding in vivo interaction partners, such as lipids or proteins. Furthermore, the LTPs have several properties, such as the promiscuous lipid binding, flexible binding cavity, and the extreme thermostability, which could open up for valuable applications in the development of biosensors and nanomaterials (Pagano et al. 2013). We expect that the next few years will be a very productive and exciting period for the LTP research.

Acknowledgments We thank Cajsa Lithell for designing and drawing Figure 9. Work in the authors labs were supported by Carl Tryggers Stiftelse. Use of Biocenter Finland infrastructure at Åbo
Akademi (bioinformatics, structural biology, and translational activities) is acknowledged.

Open Access This article is distributed under the terms of the Creative Commons Attribution 4.0 International License (http://crea tivecommons.org/licenses/by/4.0/), which permits unrestricted use, distribution, and reproduction in any medium, provided you give appropriate credit to the original author(s) and the source, provide a link to the Creative Commons license, and indicate if changes were made.

\section{References}

Akkerdaas J, Finkina EI, Balandin SV, Santos Magadán S, Knulst A, Fernandez-Rivas M, Asero R, van Ree R, Ovchinnikova TV (2012) Lentil (Lens culinaris) lipid transfer protein Len c 3: a novel legume allergen. Int Arch Allergy Immunol 157:51-57

Allen AM, Lexer C, Hiscock SJ (2010) Comparative analysis of pistil transcriptomes reveals conserved and novel genes expressed in dry, wet, and semidry stigmas. Plant Physiol 154:1347-1360

Arondel V, Vergnolle C, Cantrel C, Kader J (2000) Lipid transfer proteins are encoded by a small multigene family in Arabidopsis thaliana. Plant Sci 157:1-12

Bakan B, Hamberg M, Perrocheau L, Maume D, Rogniaux H, Tranquet O, Rondeau C, Blein JP, Ponchet M, Marion D (2006) Specific adduction of plant lipid transfer protein by an allene oxide generated by 9-lipoxygenase and allene oxide synthase. J Biol Chem 281:38981-38988

Berecz B, Mills EN, Tamás L, Láng F, Shewry PR, Mackie AR (2010) Structural stability and surface activity of sunflower $2 \mathrm{~S}$ albumins and nonspecific lipid transfer protein. J Agric Food Chem 58:6490-6497

Boutrot F, Meynard D, Guiderdoni E, Joudrier P, Gautier MF (2007) The Triticum aestivum non-specific lipid transfer protein (TaLtp) gene family: comparative promoter activity of six TaLtp genes in transgenic rice. Planta 225:843-862

Boutrot F, Chantret N, Gautier MF (2008) Genome-wide analysis of the rice and Arabidopsis non-specific lipid transfer protein (nsLtp) gene families and identification of wheat nsLtp genes by EST data mining. BMC Genom 9:86

Buhot N, Gomes E, Milat ML, Ponchet M, Marion D, Lequeu J, Delrot S, Coutos-Thevenot P, Blein JP (2004) Modulation of the biological activity of a tobacco LTP1 by lipid complexation. Mol Biol Cell 15:5047-5052

Carvalho AO, Souza-Filho GA, Ferreira BS, Branco AT, Araújo IS, Fernandes KV, Retamal CA, Gomes VM (2006) Cloning and characterization of a cowpea seed lipid transfer protein cDNA: expression analysis during seed development and under fungal and cold stresses in seedlings' tissues. Plant Physiol Biochem 44:732-742

Chae K, Kieslich CA, Morikis D, Kim SC, Lord EM (2009) A gainof-function mutation of Arabidopsis lipid transfer protein 5 disturbs pollen tube tip growth and fertilization. Plant Cell 21:3902-3914

Chae K, Gonong BJ, Kim SC, Kieslich CA, Morikis D, Balasubramanian S, Lord EM (2010) A multifaceted study of stigma/style cysteine-rich adhesin (SCA)-like Arabidopsis lipid transfer proteins (LTPs) suggests diversified roles for these LTPs in plant growth and reproduction. J Exp Bot 61:4277-4290

Champigny MJ, Isaacs M, Carella P, Faubert J, Fobert PR, Cameron RK (2013) Long distance movement of DIR1 and investigation of the role of DIR1-like during systemic acquired resistance in Arabidopsis. Front Plant Sci 4:230 
Charvolin D, Douliez JP, Marion D, Cohen-Addad C, Pebay-Peyroula E (1999) The crystal structure of a wheat nonspecific lipid transfer protein (ns-LTP1) complexed with two molecules of phospholipid at 2.1 A resolution. Eur J Biochem 264:562-568

Chen C, Chen G, Hao X, Cao B, Chen Q, Liu S, Lei J (2011) CaMF2, an anther-specific lipid transfer protein (LTP) gene, affects pollen development in Capsicum annиит L. Plant Sci 181:439-448

Cheng CS, Samuel D, Liu YJ, Shyu JC, Lai SM, Lin KF, Lyu PC (2004a) Binding mechanism of nonspecific lipid transfer proteins and their role in plant defense. Biochemistry 43:13628-13636

Cheng HC, Cheng PT, Peng P, Lyu PC, Sun YJ (2004b) Lipid binding in rice nonspecific lipid transfer protein-1 complexes from Oryza sativa. Protein Sci 13:2304-2315

Cheng CS, Chen MN, Lai YT, Chen T, Lin KF, Liu YJ, Lyu PC (2008) Mutagenesis study of rice nonspecific lipid transfer protein 2 reveals residues that contribute to structure and ligand binding. Proteins 70:695-706

Choi YE, Lim S, Kim HJ, Han JY, Lee MH, Yang Y, Kim JA, Kim YS (2012) Tobacco NtLTP1, a glandular-specific lipid transfer protein, is required for lipid secretion from glandular trichomes. Plant J 70:480-491

Cotta MG, Barros LM, de Almeida JD, de Lamotte F, Barbosa EA, Vieira NG, Alves GS, Vinecky F, Andrade AC, Marraccini P (2014) Lipid transfer proteins in coffee: isolation of Coffea orthologs, Coffea arabica homeologs, expression during coffee fruit development and promoter analysis in transgenic tobacco plants. Plant Mol Biol 85:11-31

Da Silva P, Landon C, Industri B, Marais A, Marion D, Ponchet M, Vovelle F (2005) Solution structure of a tobacco lipid transfer protein exhibiting new biophysical and biological features. Proteins 59:356-367

D'Agostino N, Pizzichini D, Chiusano ML, Giuliano G (2007) An EST database from saffron stigmas. BMC Plant Biol 7:53

Debono A, Yeats TH, Rose JK, Bird D, Jetter R, Kunst L, Samuels L (2009) Arabidopsis LTPG is a glycosylphosphatidylinositolanchored lipid transfer protein required for export of lipids to the plant surface. Plant Cell 21:1230-1238

Douliez JP, Michon T, Marion D (2000) Steady-state tyrosine fluorescence to study the lipid-binding properties of a wheat nonspecific lipid-transfer protein (nsLTP1). Biochim Biophys Acta 1467:65-72

Douliez JP, Pato C, Rabesona H, Mollé D, Marion D (2001) Disulfide bond assignment, lipid transfer activity and secondary structure of a 7-kDa plant lipid transfer protein, LTP2. Eur J Biochem 268:1400-1403

Edqvist J, Farbos I (2002) Characterization of germination-specific lipid transfer proteins from Euphorbia lagascae. Planta 215:41-50

Edqvist J, Ronnberg E, Rosenquist S, Blomqvist K, Viitanen L, Salminen TA, Nylund M, Tuuf J, Mattjus P (2004) Plants express a lipid transfer protein with high similarity to mammalian sterol carrier protein-2. J Biol Chem 279:53544-53553

Edstam MM, Edqvist J (2014) Involvement of GPI-anchored lipid transfer proteins in the development of seed coats and pollen in Arabidopsis thaliana. Physiol Plant 152:32-42

Edstam MM, Viitanen L, Salminen TA, Edqvist J (2011) Evolutionary history of the non-specific lipid transfer proteins. Mol Plant 4:947-964

Edstam MM, Blomqvist K, Eklöf A, Wennergren U, Edqvist J (2013) Coexpression patterns indicate that GPI-anchored non-specific lipid transfer proteins are involved in accumulation of cuticular wax, suberin and sporopollenin. Plant Mol Biol 83:625-649

Edstam MM, Laurila M, Höglund A, Raman A, Dahlström KM, Salminen TA, Edqvist J, Blomqvist K (2014) Characterization of the GPI-anchored lipid transfer proteins in the moss Physcomitrella patens. Plant Physiol Biochem 75:55-69

Egger M, Hauser M, Mari A, Ferreira F, Gadermaier G (2010) The role of lipid transfer proteins in allergic diseases. Curr Allergy Asthma Rep 10:326-335

Eklund DM, Edqvist J (2003) Localization of non-specific lipid transfer proteins correlate with programmed cell death responses during endosperm degradation in Euphorbia lagascae seedlings. Plant Physiol 132:1249-1259

Fernández-Rivas M, González-Mancebo E, Rodríguez-Pérez R, Benito C, Sánchez-Monge R, Salcedo G, Alonso MD, Rosado A, Tejedor MA, Vila C, Casas ML (2003) Clinically relevant peach allergy is related to peach lipid transfer protein, Pru $\mathrm{p} 3$, in the Spanish population. J Allergy Clin Immunol 112:789-795

Finkina EI, Balandin SV, Serebryakova MV, Potapenko NA, Tagaev AA, Ovchinnikova TV (2007) Purification and primary structure of novel lipid transfer proteins from germinated lentil (Lens culinaris) seeds. Biochemistry (Mosc) 72:430-438

Gao QM, Kachroo A, Kachroo P (2014) Chemical inducers of systemic immunity in plants. J Exp Bot 65:1849-1855

Gaudet DA, Laroche A, Frick M, Huel R, Puchalski B (2003) Cold induced expression of plant defensin and lipid transfer protein transcripts in winter wheat. Physiol Plant 117:195-205

Gincel E, Simorre JP, Caille A, Marion D, Ptak M, Vovelle F (1994) Three-dimensional structure in solution of a wheat lipid-transfer protein from multidimensional $1 \mathrm{H}-\mathrm{NMR}$ data. A new folding for lipid carriers. Eur J Biochem 226:413-422

Gizatullina AK, Finkina EI, Mineev KS, Melnikova DN, Bogdanov IV, Telezhinskaya IN, Balandin SV, Shenkarev ZO, Arseniev AS, Ovchinnikova TV (2013) Recombinant production and solution structure of lipid transfer protein from lentil Lens culinaris. Biochem Biophys Res Commun 439:427-432

Gomar J, Petit MC, Sodano P, Sy D, Marion D, Kader JC, Vovelle F, Ptak M (1996) Solution structure and lipid binding of a nonspecific lipid transfer protein extracted from maize seeds. Protein Sci 5:565-577

Guerbette F, Grosbois M, Jolliot-Croquin A, Kader JC, Zachowski A (1999a) Comparison of lipid binding and transfer properties of two lipid transfer proteins from plants. Biochemistry 38:14131-14137

Guerbette F, Grosbois M, Jolliot-Croquin A, Kader JC, Zachowski A (1999b) Lipid-transfer proteins from plants: structure and binding properties. Mol Cell Biochem 192:157-161

Guo C, Ge X, Ma H (2013a) The rice OsDIL gene plays a role in drought tolerance at vegetative and reproductive stages. Plant Mol Biol 82:239-253

Guo L, Yang H, Zhang X, Yang S (2013b) Lipid transfer protein 3 as a target of MYB96 mediates freezing and drought stress in Arabidopsis. J Exp Bot 64:1755-1767

Han GW, Lee JY, Song HK, Chang C, Min K, Moon J, Shin DH, Kopka ML, Sawaya MR, Yuan HS, Kim TD, Choe J, Lim D, Moon HJ, Suh SW (2001) Structural basis of non-specific lipid binding in maize lipid-transfer protein complexes revealed by high-resolution X-ray crystallography. J Mol Biol 308:263-278

Heinemann B, Andersen KV, Nielsen PR, Bech LM, Poulsen FM (1996) Structure in solution of a four-helix lipid binding protein. Protein Sci 5:13-23

Hoh F, Pons JL, Gautier MF, de Lamotte F, Dumas C (2005) Structure of a liganded type 2 non-specific lipid-transfer protein from wheat and the molecular basis of lipid binding. Acta Crystallogr D Biol Crystallogr 61:397-406

Hollenbach B, Schreiber L, Hartung W, Dietz KJ (1997) Cadmium leads to stimulated expression of the lipid transfer protein genes in barley: implications for the involvement of lipid transfer proteins in wax assembly. Planta 203:9-19 
Huang MD, Chen TL, Huang AH (2013) Abundant type III lipid transfer proteins in Arabidopsis tapetum are secreted to the locule and become a constituent of the pollen exine. Plant Physiol 163:1218-1229

Jang CS, Johnson JW, Seo YW (2005) Differential expression of TaLTP 3 and TaCOMT1 induced by Hessian fly larval infestation in a wheat line possessing $\mathrm{H} 21$ resistance gene. Plant Sci 168:1319-1326

Joly V, Matton DP (2015) KAPPA, a simple algorithm for discovery and clustering of proteins defined by a key amino acid pattern: a case study of the cysteine-rich proteins. Bioinformatics 31:1716-1723

Jung SH, Lee JY, Lee DH (2003) Use of SAGE technology to reveal changes in gene expression in Arabidopsis leaves undergoing cold stress. Plant Mol Biol 52:553-567

Jung HW, Tschaplinski TJ, Wang L, Glazebrook J, Greenberg JT (2009) Priming in systemic plant immunity. Science 324:89-91

Kader JC (1996) Lipid-transfer proteins in plants. Annu Rev Plant Physiol Plant Mol Biol 47:627-654

Kalla R, Shimamoto K, Potter R, Nielsen PS, Linnestad C, Olsen OA (1994) The promoter of the barley aleurone-specific gene encoding a putative $7 \mathrm{kDa}$ lipid transfer protein confers aleurone cell-specific expression in transgenic rice. Plant J 6:849-856

Kim H, Lee SB, Kim HJ, Min MK, Hwang I, Suh MC (2012) Characterization of glycosylphosphatidylinositol-anchored lipid transfer protein 2 (LTPG2) and overlapping function between LTPG/LTPG1 and LTPG2 in cuticular wax export or accumulation in Arabidopsis thaliana. Plant Cell Physiol 53:1391-1403

Kirubakaran SI, Begum SM, Ulaganathan K, Sakthivel N (2008) Characterization of a new antifungal lipid transfer protein from wheat. Plant Physiol Biochem 46:918-927

Kovalchuk N, Smith J, Pallotta M, Singh R, Ismagul A, Eliby S, Bazanova N, Milligan AS, Hrmova M, Langridge P, Lopato S (2009) Characterization of the wheat endosperm transfer cellspecific protein TaPR60. Plant Mol Biol 71:81-98

Kovalchuk N, Smith J, Bazanova N, Pyvovarenko T, Singh R, Shirley N, Ismagul A, Johnson A, Milligan AS, Hrmova M, Langridge P, Lopato S (2012) Characterization of the wheat gene encoding a grain-specific lipid transfer protein TdPR61, and promoter activity in wheat, barley and rice. J Exp Bot 63:2025-2040

Lascombe MB, Bakan B, Buhot N, Marion D, Blein JP, Larue V, Lamb C, Prange T (2008) The structure of "defective in induced resistance" protein of Arabidopsis thaliana, DIR1, reveals a new type of lipid transfer protein. Protein Sci 17:1522-1530

Lee JY, Min K, Cha H, Shin DH, Hwang KY, Suh SW (1998) Rice non-specific lipid transfer protein: the $1.6 \mathrm{~A}$ crystal structure in the unliganded state reveals a small hydrophobic cavity. J Mol Biol 276:437-448

Lee SB, Go YS, Bae HJ, Park JH, Cho SH, Cho HJ, Lee DS, Park OK, Hwang I, Suh M (2009) Disruption of glycosylphosphatidylinositol-anchored lipid transfer protein gene altered cuticular lipid composition, increased plastoglobules, and enhanced susceptibility to infection by the fungal pathogen Alternaria brassicicola. Plant Physiol 150:42-54

Lei L, Chen L, Shi X, Li Y, Wang J, Chen D, Xie F, Li Y (2014) A nodule-specific lipid transfer protein AsE246 participates in transport of plant-synthesized lipids to symbiosome membrane and is essential for nodule organogenesis in Chinese milk vetch. Plant Physiol 164:1045-1058

Lerche MH, Poulsen FM (1998) Solution structure of barley lipid transfer protein complexed with palmitate. Two different binding modes of palmitate in the homologous maize and barley nonspecific lipid transfer proteins. Protein Sci 7:2490-2498

Lerche MH, Kragelund BB, Bech LM, Poulsen FM (1997) Barley lipid-transfer protein complexed with palmitoyl CoA: the structure reveals a hydrophobic binding site that can expand to fit both large and small lipid-like ligands. Structure 5:291-306
Li C, Xie W, Bai W, Li Z, Zhao Y, Liu H (2008) Calmodulin binds to maize lipid transfer protein and modulates its lipids binding ability. FEBS J 275:5298-5330

Li J, Gao G, Xu K, Chen B, Yan G, Li F, Qiao J, Zhang T, Wu X (2014a) Genome-wide survey and expression analysis of the putative non-specific lipid transfer proteins in Brassica rapa L. PLoS One 9:e84556

Li M, Lopato S, Hrmova M, Pickering M, Shirley N, Koltunow AM, Langridge P (2014b) Expression patterns and protein structure of a lipid transfer protein END1 from Arabidopsis. Planta 240:1319-1334

Lin KF, Liu YN, Hsu ST, Samuel D, Cheng CS, Bonvin AM, Lyu PC (2005) Characterization and structural analyses of nonspecific lipid transfer protein 1 from mung bean. Biochemistry 44:5703-5712

Lindorff-Larsen K, Winther JR (2001) Surprisingly high stability of barley lipid transfer protein, LTP1, towards denaturant, heat and proteases. FEBS Lett 488:145-148

Lindorff-Larsen K, Lerche MH, Poulsen FM, Roepstorff P, Winther JR (2001) Barley lipid transfer protein, LTP1, contains a new type of lipid-like post-translational modification. J Biol Chem 276:33547-33553

Liu KH, Lin TY (2003) Cloning and characterization of two novel lipid transfer protein I genes in Vigna radiata. DNA Seq $14: 420-426$

Liu X, Shangguan Y, Zhu J, Lu Y, Han B (2013) The rice OsLTP6 gene promoter directs anther-specific expression by a combination of positive and negative regulatory elements. Planta 238:845-857

Liu F, Xiong X, Wu L, Fu D, Hayward A, Zeng X, Cao Y, Wu Y, Li Y, Wu G (2014) BraLTP1, a lipid transfer protein gene involved in epicuticular wax deposition, cell proliferation and flower development in Brassica napus. PLoS One 9:e110272

Maldonado AM, Doerner P, Dixon RA, Lamb CJ, Cameron RK (2002) A putative lipid transfer protein involved in systemic resistance signalling in Arabidopsis. Nature 419:399-403

Masuta C, Furuno M, Tanaka H, Yamada M, Koiwai A (1992) Molecular cloning of a cDNA clone for tobacco lipid transfer protein and expression of the functional protein in Escherichia coli. FEBS Lett 311:119-123

Nieuwland J, Feron R, Huisman BA, Fasolino A, Hilbers CW, Derksen J, Mariani C (2005) Lipid transfer proteins enhance cell wall extension in tobacco. Plant Cell 17:2009-2019

Offermann LR, Bublin M, Perdue ML, Pfeifer S, Dubiela P, Borowski T, Chruszcz M, Hoffmann-Sommergruber K (2015) Structural and functional characterization of the hazelnut allergen Cor a 8 . J Agric Food Chem 63:9150-9158

Pagano K, Tomaselli S, Zanzoni S, Assfalg M, Molinari H, Ragona L (2013) Bile acid binding protein: a versatile host of small hydrophobic ligands for applications in the fields of MRI contrast agents and bio-nanomaterials. Comput Struct Biotechnol J 6:e201303021

Park SY, Jauh GY, Mollet JC, Eckard KJ, Nothnagel EA, Walling LL, Lord EM (2000) A lipid transfer-like protein is necessary for lily pollen tube adhesion to an in vitro stylar matrix. Plant Cell 12:151-164

Pasquato N, Berni R, Folli C, Folloni S, Cianci M, Pantano S, Helliwell JR, Zanotti G (2006) Crystal structure of peach Pru p 3, the prototypic member of the family of plant non-specific lipid transfer protein pan-allergens. J Mol Biol 356:684-694

Pastorello EA, Farioli L, Pravettoni V, Ispano M, Scibola E, Trambaioli C, Giuffrida MG, Ansaloni R, Godovac-Zimmermann J, Conti A, Fortunato D, Ortolani C (2000) The maize major allergen, which is responsible for food-induced allergic reactions, is a lipid transfer protein. J Allergy Clin Immunol 106:744-751 
Perrocheau L, Bakan B, Boivin P, Marion D (2006) Stability of barley and malt lipid transfer protein 1 (LTP1) toward heating and reducing agents: relationships with the brewing process. J Agric Food Chem 54:3108-3113

Pii Y, Astegno A, Peroni E, Zaccardelli M, Pandolfini T, Crimi M (2009) The Medicago truncatula N5 gene encoding a rootspecific lipid transfer protein is required for the symbiotic interaction with Sinorhizobium meliloti. Mol Plant Microbe Interact 22:1577-1587

Pii Y, Molesini B, Masiero S, Pandolfini T (2012) The non-specific lipid transfer protein N5 of Medicago truncatula is implicated in epidermal stages of rhizobium-host interaction. BMC Plant Biol $12: 233$

Pons JL, de Lamotte F, Gautier MF, Delsuc MA (2003) Refined solution structure of a liganded type 2 wheat nonspecific lipid transfer protein. J Biol Chem 278:14249-14256

Poznanski J, Sodano P, Suh SW, Lee JY, Ptak M, Vovelle F (1999) Solution structure of a lipid transfer protein extracted from rice seeds. Comparison with homologous proteins. Eur J Biochem 259:692-708

Quiapim AC, Brito MS, Bernardes LA, Dasilva I, Malavazi I, DePaoli HC, Molfetta-Machado JB, Giuliatti S, Goldman GH, Goldman MH (2009) Analysis of the Nicotiana tabacum stigma/style transcriptome reveals gene expression differences between wet and dry stigma species. Plant Physiol 149:1211-1230

Royo J, Gómez E, Sellam O, Gerentes D, Paul W, Hueros G (2014) Two maize END-1 orthologs, BETL9 and BETL9like, are transcribed in a non-overlapping spatial pattern on the outer surface of the developing endosperm. Front Plant Sci 5:180

Salcedo G, Sánchez-Monge R, Barber D, Díaz-Perales A (2007) Plant non-specific lipid transfer proteins: an interface between plant defence and human allergy. Biochim Biophys Acta 1771:781-791

Saltzmann KD, Giovanini MP, Ohm HW, Williams CE (2010) Transcript profiles of two wheat lipid transfer protein-encoding genes are altered during attack by Hessian fly larvae. Plant Physiol Biochem 48:54-61

Samuel D, Liu YJ, Cheng CS, Lyu PC (2002) Solution structure of plant nonspecific lipid transfer protein-2 from rice (Oryza sativa). J Biol Chem 277:35267-35273

Sawano Y, Hatano K, Miyakawa T, Komagata H, Miyauchi Y, Yamazaki H, Tanokura M (2008) Proteinase inhibitor from ginkgo seeds is a member of the plant nonspecific lipid transfer protein gene family. Plant Physiol 146:1909-1919

Schweiger W, Steiner B, Ametz C, Siegwart G, Wiesenberger G, Berthiller F, Lemmens M, Jia H, Adam G, Muehlbauer GJ, Kreil DP, Buerstmayr H (2013) Transcriptomic characterization of two major Fusarium resistance quantitative trait loci (QTLs), Fhb1 and Qfhs.ifa-5A, identifies novel candidate genes. Mol Plant Pathol 14:772-785

Shang KJ, Ling QL, Li CF, Cao YJ (1991) A novel calmodulin binding protein in plants. Acta Biochim Biophys Sin 23:416-422

Shin DH, Lee JY, Hwang KY, Kim KK, Suh SW (1995) Highresolution crystal structure of the non-specific lipid-transfer protein from maize seedlings. Structure 3:189-199

Simorre JP, Caille A, Marion D, Marion D, Ptak M (1991) Two- and three-dimensional $1 \mathrm{H}$ NMR studies of a wheat phospholipid transfer protein: sequential resonance assignments and secondary structure. Biochemistry 30:11600-11608

Smith LJ, Roby Y, Allison JR, van Gunsteren WF (2013) Molecular dynamics simulations of barley and maize lipid transfer proteins show different ligand binding preferences in agreement with experimental data. Biochemistry 52:5029-5038

Smyth DR, Bowman JL, Meyerowitz EM (1990) Early flower development in Arabidopsis. Plant Cell 2:755-767

Sodano P, Caille A, Sy D, de Person G, Marion D, Ptak M (1997) 1H NMR and fluorescence studies of the complexation of DMPG by wheat non-specific lipid transfer protein. Global fold of the complex. FEBS Lett 416:130-134

Sun JY, Gaudet DA, Lu ZX, Frick M, Puchalski B, Laroche A (2008) Characterization and antifungal properties of wheat nonspecific lipid transfer proteins. Mol Plant Microbe Interact 21:346-360

Swanson R, Clark T, Preuss D (2005) Expression profiling of Arabidopsis stigma tissue identifies stigma-specific genes. Sex Plant Reprod 18:163-171

Tapia G, Morales-Quintana L, Parra C, Berbel A, Alcorta M (2013) Study of nsLTPs in Lotus japonicus genome reveal a specific epidermal cell member (LjLTP10) regulated by drought stress in aerial organs with a putative role in cutin formation. Plant Mol Biol 82:485-501

Tassin-Moindrot S, Caille A, Douliez JP, Marion D, Vovelle F (2000) The wide binding properties of a wheat nonspecific lipid transfer protein. Solution structure of a complex with prostaglandin B2. Eur J Biochem 267:1117-1124

Van Winkle RC, Chang C (2014) The biochemical basis and clinical evidence of food allergy due to lipid transfer proteins: a comprehensive review. Clin Rev Allergy Immunol 46:211-224

Vishwanath SJ, Delude C, Domergue F, Rowland O (2015) Suberin: biosynthesis, regulation, and polymer assembly of a protective extracellular barrier. Plant Cell Rep 34:573-586

Wang Z, Xie W, Chi F, Li C (2005) Identification of non-specific lipid transfer protein-1 as a calmodulin-binding protein in Arabidopsis. FEBS Lett 579:1683-1687

Wang HW, Kwon HJ, Yim WC, Lim SD, Moon JC, Lee BM, Seo YW, Kim W, Jang CS (2010) Expressional diversity of wheat nsLTP genes: evidence of subfunctionalization via cis-regulatory divergence. Genetica 138:843-852

Wei K, Zhong X (2014) Non-specific lipid transfer proteins in maize. BMC Plant Biol 14:281

Wellman CH, Osterloff PL, Mohiuddin U (2003) Fragments of the earliest land plants. Nature 425:282-285

Yu K, Soares JM, Mandal MK, Wang C, Chanda B, Gifford AN, Fowler JS, Navarre D, Kachroo A, Kachroo P (2013) A feedback regulatory loop between G3P and lipid transfer proteins DIR1 and AZI1 mediates azelaic-acid-induced systemic immunity. Cell Rep 3:1266-1278

Yu G, Hou W, Du X, Wang L, Wu H, Zhao L, Kong L, Wang H (2014) Identification of wheat non-specific lipid transfer proteins involved in chilling tolerance. Plant Cell Rep 33:1757-1766

Zachowski A, Guerbette F, Grosbois M, Jolliot-Croquin A, Kader JC (1998) Characterisation of acyl binding by a plant lipid-transfer protein. Eur J Biochem 257:443-448

Zhang D, Wilson ZA (2009) Stamen specification and anther development in rice. Chin Sci Bull 54:2342-2353

Zhang D, Liang W, Yin C, Zong J, Gu F, Zhang D (2010) OsC6, encoding a lipid transfer protein, is required for postmeiotic anther development in rice. Plant Physiol 154:149-162

Zhu X, Li Z, Xu H, Zhou M, Du L, Zhang Z (2012) Overexpression of wheat lipid transfer protein gene TaLTP5 increases resistances to Cochliobolus sativus and Fusarium graminearum in transgenic wheat. Funct Integr Genomics 12:481-488 